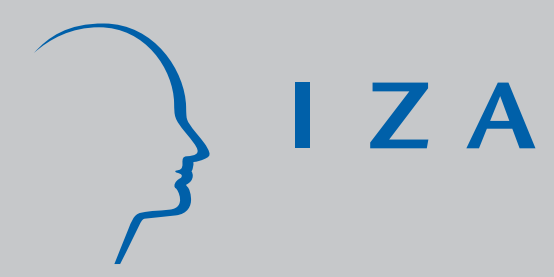

IZA DP No. 690

Contracting with Private Information

Marcus Hagedorn

J anuary 2003 


\title{
Contracting with Private Information
}

\author{
Marcus Hagedorn \\ University of Bonn \\ and IZA Bonn
}

Discussion Paper No. 690
January 2003

IZA

P.O. Box 7240

D-53072 Bonn

Germany

Tel.: +49-228-3894-0

Fax: +49-228-3894-210

Email: iza@iza.org

This Discussion Paper is issued within the framework of IZA's research area Mobility and Flexibility of Labor. Any opinions expressed here are those of the author(s) and not those of the institute. Research disseminated by IZA may include views on policy, but the institute itself takes no institutional policy positions.

The Institute for the Study of Labor (IZA) in Bonn is a local and virtual international research center and a place of communication between science, politics and business. IZA is an independent, nonprofit limited liability company (Gesellschaft mit beschränkter Haftung) supported by the Deutsche Post AG. The center is associated with the University of Bonn and offers a stimulating research environment through its research networks, research support, and visitors and doctoral programs. IZA engages in (i) original and internationally competitive research in all fields of labor economics, (ii) development of policy concepts, and (iii) dissemination of research results and concepts to the interested public. The current research program deals with (1) mobility and flexibility of labor, (2) internationalization of labor markets, (3) welfare state and labor market, (4) labor markets in transition countries, (5) the future of labor, (6) evaluation of labor market policies and projects and (7) general labor economics.

IZA Discussion Papers often represent preliminary work and are circulated to encourage discussion. Citation of such a paper should account for its provisional character. A revised version may be available on the IZA website (www.iza.org) or directly from the author. 
IZA Discussion Paper No. 690 January 2003

\section{ABSTRACT}

\section{Contracting with Private Information*}

This paper adds to the current literature on incomplete contracting that argues that deviating from a complete information, transaction-cost free environment may be may generate valuable insights. We achieve this by assuming bargaining with asymmetric information. We consider the consequences of asymmetric information for investment decisions and for the assignment of property rights. This analysis is crucial since any foundation must ensure that results of the kind derived by Grossman, Hart and Moore still hold. It is shown that investment incentives are guided by an additional element to standard hold-up models since the outcome of bargaining depends directly on the investment level. This may for example result in cooperative overinvestment. Although investment incentives are always positive from a social perspective, they can be negative from an individual's perspective. In our model, property rights are shown to still play a role. This arises from their tight interaction with ex-post bargaining. Optimal ownership structures are characterized and a new role for option contracts is identified.

JEL Classification: D23, D81, D82, L14

Keywords: private values, ownership, property rights, incomplete contracts, hold-up

Marcus Hagedorn

Institute for the Study of Labor (IZA)

P.O. Box 7240

53072 Bonn

Germany

Email: hagedorn@iza.org

\footnotetext{
* I am grateful to Bert Füssenich, Christoph Lülfesmann, Georg Nöldeke und Patrick Schmitz for helpful comments on an earlier draft. I am solely responsible for any remaining errors.
} 


\section{Introduction}

This paper adds to the current literature on incomplete contracting that argues that deviating from a complete information, transaction-cost free environment may generate valuable insights. In this model this is achieved by assuming bargaining with asymmetric information. We believe, in light of the papers by Hart and Moore (1998,1999), Maskin and Tirole (1999a,b), Reiche (2001) and Hagedorn (2001), that asymmetric information may be a necessary, or at least a helpful, ingredient when approaching a possible foundation of incomplete contracts. A model with asymmetric information first renders implementation harder and second makes foreseeing all future (implementable) utilities a less compelling assumption. Tackling the Maskin/Tirole-critique, which roughly states that unforeseen contingencies do not matter in the presence of rational individuals, will presumably become easier. Working with asymmetric instead of symmetric information gives us some hope that less structured environments can provide a foundation. This paper is a first step within a larger research project that aims to incorporate asymmetric information into a standard hold-up model to find reasons for the prevailing incompleteness of contracts.

Furthermore, most of the literature on incomplete contracting, which assumes that the set of possible contracts is exogenously given, has followed the seminal papers by Grossmann \& Hart(1986) and Hart \& Moore (1990). They all assume that bargaining takes place with symmetric information. On the other hand, asymmetric information is considered to be a valuable ingredient in several other strands of literature, e.g. in regulation, procurement or optimal taxation. One may then ask why asymmetric information should be crucial when a firm is regulated by a government agency but should be irrelevant when this firm contracts with another firm. Neither the agency nor the potential trading partner can have perfect information about the firm's cost structure. Thus the question is whether the restriction to symmetric information is only one of many possible environments or whether all essential insights can already be grasped without resorting to asymmetric information. The main contribution of this paper is to work out the consequences of asymmetric information at the bargaining stage for investment and for the value of various ownership structures.

The literature on bilateral trade models has focused so far on the hold-up problem, which arises from the interplay of the specificity of investments and the incompleteness of contracts. Thereby renegotiation and the Coase Theorem (and no transaction costs) ensure ex-post efficiency. The main problem is the mitigation of underinvestment. This emerges whenever investment creates more value inside a relationship than outside such that opportunistic behavior deprives the investor of the 
full marginal return of his investment. The literature proposes various remedies to this inefficiency, such as shifts in property rights or simple contracts. In this paper we add to this literature by considering the possibility of organisational interventions, specifically of changing property rights, as ways of mitigating inefficiencies arising in bilateral trade frameworks. However, we not only focus on the optimality of investment decisions but also concentrate on the inefficiencies arising from asymmetric information at the ex-post bargaining stage. Thus different forms of ownership structure are evaluated not only from an investment perspective but also from a bargaining perspective.

This paper uses the Grossman-Hart-Moore "hold-up" / "property rights" framework $^{1}$, but with asymmetric information at the ex-post bargaining stage. We restrict our analysis to two agents (a buyer and a seller), who, after having agreed on the ownership structure and/or having made their investment decisions, bargain about the trade volume and the money compensation with two-sided private information. The analysis of the consequences of asymmetric information has two main parts. In the first part, which comprises sections 3.1 to 3.3, we characterize the (constrained efficient) result of bargaining and determine the investment incentives for both agents. We show that investment behavior is guided by two main effects.

First we identify the (standard) externality hold-up effect. Both agents ignore benefits (and losses) they cause on their trading partners. This results in the well-known deviation from the maximization of the social surplus by the agents.

Second we find the bargaining hold-up effect. Thereby changing investment changes the bargaining outcome. This is different from standard hold-up models with symmetric information where the allocation maximizes ex-post surplus which is independent of the specific distribution of valuations. But with asymmetric information the agents are eager to avoid e.g. paying a high compensation to a low cost seller. This two-sided quarrel results in inefficiencies which are not independent of the beliefs of the agents, which are updated after having observed the investment level. The buyer's willingness to generously compensate a seller depends on his beliefs about the cost level of the seller. The higher the investment the more confident the buyer will be that the seller has only low costs and the less willing he will be to accept a high price. He then prefers to haggle.

\footnotetext{
${ }^{1}$ Introduced in the seminal paper by Grossman and Hart (1986) and in a more general setting by Hart and Moore (1990).
} 
Comparing these investment incentives to a first best benchmark gives the result that, contrary to the growing consensus in the literature (e.g. Che and Hausch (1999) and Edlin and Hermalin (1996) ), the incentives for cooperative investment are neither necessarily lower than those for selfish investment nor always lower than the first best incentives. Thus the agents may cooperatively overinvest. On the other hand their incentives for selfish investment may be negative although a positive investment level is beneficial from a social perspective. These statements are strengthened in section 3.3, when we allow for some correlation among the agents' private signals. It will be shown that situations can arise which are characterized by joint cooperative overinvestment. In the second part we consider the effects of different property rights. We have to distinguish between two cases, which differ with respect to their (implicit) assumptions on the renegotiation proofness of property rights. On the one hand, we allow for and discuss perfect commitment to an assignment of property rights, and on the other hand, we allow for no commitment at all. Property rights pin down the agent who is entitled to use the asset when no trade takes place or has not yet taken place. Assets are crucial both for the buyer and the seller to produce or process the good. Assigning property rights to one agent then has the following consequences:

First, utility increases in case of a delay of trade since the owner uses this asset in the meanwhile.

Second, the need to reach an agreement becomes less urgent as delay is then less costly.

Third, the owner of the assets will demand a higher share of the surplus since his threat point improves. Delaying trade becomes less costly. This will intensify the quarrel.

Fourth, if an agent with a low cost level gains more by exercising the inside option than an agent with a high cost level, his costs of delay decrease disproportionately. This makes a low cost agent less willing to accept a bad offer but more willing to haggle for his share of the surplus.

An efficient assignment of property rights then trades off these four effects. This allows us to answer the question about the optimal ownership structure of a firm. In principle three possibilities emerge. Either the seller can own all assets (sellerintegration) or they can share the assets (non-integration) or the buyer can own all assets (buyer-integration). We show that both integration ownership and nonintegration can be an optimal assignement of property, depending on the magnitudes 
of these four effects. In the case of no commitment we show that an option contract can be optimal. An option contract on the ownership of assets is not necessarily a definitive assignment but gives the owner the right to refuse a change in assets. Furthermore we show that property rights influence gains from trade and that the level of asset specificity has an influence on the allocation of ownership and investment behavior. Moreover assigning only a fraction of a firm's equity to one party in a multi-asset framework can be optimal.

Apart from the vast literature on the hold-up problem with efficient ex-post bargaining $^{2}$ there are only a few papers considering asymmetric information at the ex-post stage. Among them Hart and Moore (1998), who assume that agents' individual preferences are privately known such that, according to the inefficiency-results in models with public goods and a large number of bidders (see Mailath and Postlewaite (1990) and Rob (1989)), there is no scope for recontracting. In contrast, in our two-agents setting, many allocations can be renegotiated, but we do not reach efficiency either. Thus we can, for example, analyze the effects of different assignments of ownership on the ex-post outcome.

Tirole (1986) also considers relationship-specific investment with asymmetric information at the bargaining stage. However, the case of observable but unverifiable investment is not at the heart of his paper. None of our results can already be found in his paper. Tirole postulates that the level of invetment should have an impact on the bargaining process so that the investor has to take this into account. This will result in what we call the bargaining hold-up effect.

Whereas Tirole (1986) only discusses investment, Matouschek $(2002)^{3}$ only deals with the assignment of property rights. Thus we will discuss his contribution in section 4 and explain which results are shown in both papers and which are new in our contribution.

The rest of the paper is organized as follows. The model is detailed in the next section. Section 3.1 presents the analysis for continously distributed valuations whereas in all the following sections we restrict ourselves to a discrete setting. In Section 3.2 the results of bargaining and investment incentives are determined for independently distributed types, and section 3.3 extends this analysis by allowing for correlated types. The second half of the paper begins in section 4. In section 4.1 property rights are incorporated into the model, and we consider two benchmarks. Section 4.2 discusses renegotiation-proof property rights and section 4.3 considers the no

\footnotetext{
${ }^{2}$ For references and insightful discussions see Edlin and Hermalin (1996) and Segal and Whinston (2000).

${ }^{3}$ I thank Patrick Schmitz for pointing my attention to this paper.
} 
commitment case. Section 4.4 analyzes the interaction of property rights and investment decisions and section 4.5 deals with the penalty doctrine and discusses Rogerson (1992).

\section{The Modeling}

We consider a bilateral trading relationship with specific investment. A seller(S) has a good for sale and faces a potential buyer(B). Both trading partners have some private information. The seller is privately informed about his marginal costs $c$ and the buyer is privately informed about his willingness to pay $v$. The agents' valuations/types $(v, c)$ are drawn from a common knowledge cumulative distribution $F_{b}(\cdot)$ on $\left[v_{1}, v_{2}\right]$ and $F_{s}(\cdot)$ on $\left[c_{1}, c_{2}\right]$, respectively. The results of bargaining are given by allocation rules. An allocation rule is any mapping from $\left[v_{1}, v_{2}\right] \times\left[c_{1}, c_{2}\right]$ to $[0,1] \times$ $\Re$. It consists of a pair $(x, t)$, where

- $x(\cdot)$ (the trading rule) maps $\left[v_{1}, v_{2}\right] \times\left[c_{1}, c_{2}\right]$ into $[0,1] . x(\cdot)$ is the probability of trade.

- $t(\cdot)$ (the payment rule) maps $\left[v_{1}, v_{2}\right] \times\left[c_{1}, c_{2}\right]$ into $\Re . t(\cdot)$ is the transfer paid by the buyer to the seller.

The agents have quasi-linear preferences $u_{B}(x, t, v)=v \cdot x-t$ and $u_{S}(x, t, c)=t-c \cdot x$, respectively. They bargain with private information. A crucial assumption in the literature is that contracts have to be renegotiation-proof. We maintain this assumption. Rubinstein \& Wolinsky (1992) identify renegotiation-proofness with efficiency in a model with symmetric information. We follow this idea and adapt it to our framework. Thus we identify renegotiation-proofness with constrained efficiency. There are several assumptions which will prevent the agents from reaching an efficient agreement. First, both agents are privately informed. Either about their marginal cost or their willingness to pay. Thus incentive constraints have to be respected. Second, individual-rationality constraints have to be taken into account ${ }^{4}$. Frequently individual-rationality constraints seem to be interpreted in a libertarian way. It is argued that these constraints do not matter if, e.g., the government has coercive power (see (12, Fudenberg,Tirole(1991))). We, in contrast, think that leaving

\footnotetext{
${ }^{4}$ To interpret the mechanism design approach we make use of the same fictitious modeling device of a benevolent third party as Laffont and Martimort (1997,2000). This third-party paradigm should be seen as a black-box for repeated interaction during bargaining. Thus we model bargaining by applying to the third party but interpret the outcome as an equilibrium of a bargaining game.
} 
the decision to participate to the agents makes sense in an (incomplete) contracting framework. Individual-rationality constraints can serve as a protection against exploitation of one party by the other through stipulating unverifiable actions, e.g. high levels of effort ${ }^{5}$. Foreseeing this potential inefficient exploitation, the agents have no incentive to commit themselves to participate. Due to unforeseen contingencies, they may be surprised by the environment that prevails at the bargaining stage, and thus the agents conclude that it is in their interest not to write a binding contract. So the individual-rationality constraint is rather an additional incentive constraint. Of course, one can think of several other "incentive interpretations" of individual-rationality constraints such as allowing for sabotage of the project by some hidden action or by allowing one party to impose high levels of effort on the other party ${ }^{6}$. Thus we impose that agents must be guaranteed at least their outside option payoff of zero. As just laid out this is a consequence of an unmodeled hidden action.

A question about the exact timing has still to be resolved. What is the first point in time at which the agents dare to commit to participate (they are then sure that no unexpected exploitation is possible) or what is the last point in time at which trade can still be prevented (through sabotage)? We follow Holmstrom and Myerson (1983) and concentrate on two stages: An interim-stage, when each individual has received his private information, but does not know the other's information. And an ex-post-stage, when the information state is public knowledge ${ }^{7}$. In the case of interim individual-rationality, for example, trade can be prevented after type realization but before the state of the world is known.

A contract $f=(x(), t())$ is called constrained efficient if it maximizes $W:=$ $\gamma E\left(u_{B}\right)+(1-\gamma) E\left(u_{S}\right)$, where $\gamma \in(0,1)$, subject to all incentive constraints and individual-rationality constraints ${ }^{8}$. The next chapter states this formally. Note that

\footnotetext{
${ }^{5}$ Bester and Strausz (2001) also impose individual rationality constraints as they deal with unverifiable actions which cannot be contractually stipulated.

${ }^{6}$ We could get rid of these assumptions about participation if we extend the model to three correlated types, such that even an ex-post Pareto-optimal Bayesian mechanism does not exist. (1, d'Aspremont,Cremer and Gerard-Varet(1990)) show that this is indeed possible for a large class of distributions.

${ }^{7}$ One can interpret ex-post individual-rationality constraints as endogenous limited liability. Thereby endogeneity refers to the fact that no outside finance is possible such that the cost must be covered by the payments and the benefits must outweigh the payments.

Assuming infinite risk-aversion provides the same constraints but would change the interim objective function.

${ }^{8} \mathrm{By}$ the revelation principle it is wlog to restrict ourselves to direct mechanisms. See Gibbard (1973), Green and Laffont (1977), Dasgupta, Hammond and Maskin (1979), Harris and Raviv (1981), Myerson (1979,1982).
} 
will restrict ourselves to $\gamma=1 / 2$ in the remainder of this paper ${ }^{9}$.

We will now lay out how we think of contracting with asymmetric information. Advocates of incomplete contracting can alternatively exclude all ex-ante contracts and "apply the Coase-Theorem" to our asymmetric information framework to conclude that at least a constrained efficient outcome is reached.

Consider now an arbitrary state-contingent contract $f=(x(), t())$. Wlog we can restrict to admissible contracts $f$, this means those contracts which fulfill incentive and individual rationality constraints. We follow Maskin \& Moore (1999) and model renegotiation as a "black box". If the contract $f$ is not constrained efficient, there are gains from renegotiation. The outcome reached in the equilibrium of the renegotiation game depends on the contract $f$. The contract $f$ changes the agents' individualrationality constraints. We will suppose that the renegotiation process $h$ leads then to the constrained efficient outcome where the outside option is determined by the contract $f$. Note that the constrained efficient outcome $h(f)=\left(x_{f}(), t_{f}()\right)$ is uniquely determined by $f$ as a solution to a Linear Programming Problem. It provides ex-ante welfare $W(f)=W(h(f))$. Decentralized bargaining may fail to achieve such outcomes, but the literature on bargaining in extensive forms (Ausubel and Deneckere (1993)) nevertheless suggests that outcomes lying on the constrained efficient Pareto frontier are feasible. Thus we suppose that the agents correctly foresee to bargain according to the rules of such an extensive form game wich leads the contract $f$ to the constrained efficient outcome.

Maskin \& Moore (1999) consider a model with symmetric information and assume that some function $h$ assigns an efficient outcome to any not Pareto optimal outcome of a contract. Thus our modeling is the analogy for asymmetric information as we have to take into account incentive compatibility. Therefore ex-ante contracts interact with ex-post efficiency and the agents try to avoid contracts that stipulate a high outside option and thus delay trade.

We can now conclude that the agents desist from writing a contract. Let $f^{0}$ be the null-contract and $h^{0}=h\left(f^{0}\right)$ the corresponding constraint efficient outcome. Consider any other admissible contract $f$. The set of constraints imposed on the maximization by the choice of $f$ can only be larger than the set of constraints imposed by the null-contract. Thus $W\left(f^{0}\right)$ will be larger than $W(f)$. But then the agents would at once tear the contract $f$ to pieces and would agree on the null-contract. Of course, this can involve some side-payments. Thus we have shown that the agents write no contract and rely on the renegotiation process. Maybe ex-ante-side-payments are necessary.

\footnotetext{
${ }^{9} \mathrm{~A}$ previous version considered also the case of unequal bargaining power.
} 
The timing is now as follows. At $t_{0}$ the agents can write a contract but as we have seen desist from writing one. At $t_{1}$ investment takes place. Investment decisions are assumed to be unverifiable (cp. (21, Hart and Moore(1988))) ${ }^{10}$. They shift the distribution of $v$ and $c$ according to first-order stochastic dominance. More precise statements are deferred to the corresponding sections. We allow for selfish and cooperative investment (see Che and Hausch (1999)). This means the investment of the buyer shifts the distribution of $v$ and $c$, respectively. And vice versa for the seller.

At $t_{2}$ types are realized. The agents know their own valuation at the interim stage $\left(t_{2}\right)$, but only know the distribution of the other agent's valuation. However, they are uninformed about the exact realization of the other agent's valuation at the interim stage. The expected utility at the interim stage is denoted $U_{b}(v)$ and $U_{s}(c)$ for $v \in\left[v_{1}, v_{2}\right]$ and $c \in\left[c_{1}, c_{2}\right]$. Thereafter, bargaining starts. Traders discount the future at interest rate $r$. Let agreement to trade between the buyer with valuation $v$ and the seller with cost $c$ be reached at time $\tau(v, c)$ at price $z(v, c) . \tau=\infty$ corresponds to the case in which agreement is never reached. Define $x(v, c):=\exp (-r \tau(v, c))$ and $t(v, c):=\exp (-r \tau(v, c)) z(v, c)$. Reaching agreement at date $\tau>0$ amounts to a probability $\exp (-r \tau)<1$ that exchange does take place in the mechanism reinterpretation ${ }^{11}$.

Thus bargaining ends at some endogenously determined date $t_{4}$.

In section 4 we allow the agents to agree on an assignment of ownership at $t_{0}$. Property rights, which entitle the agent to use the asset in case of no trade, will be modeled as changing the inside option, this means the utility as long as no trade has yet taken place. Details will be laid out in section 4 .

Let us summarize. The agents correctly foresee (for every investment decision) the allocation $(x, t)$ maximizing ex-ante expected gains from trade subject to (interim-) incentive constraints and (interim/ex-post) individual-rationality constraints $^{12}$. In addition, ex-post budget balance is required.

\footnotetext{
${ }^{10}$ This assumption facilitates the analysis in comparison to unobserved investment decisions. But allowing for mixed strategies this is no longer innocuous because a mixed strategy in a hidden action model creates asymmetric information at later stages (see Gul (2000) and e.g. Fudenberg and Tirole (1990).

${ }^{11}$ See Fudenberg and Tirole (1991) and Kennan and Wilson (1993) for this delay interpretation of a trade probability smaller than one.

${ }^{12} \mathrm{An}$ earlier version of the paper verified that our results qualitatively hold if a different solution concept to trading with asymmetric information is applied, namely unimprovable allocations (see Krasa (2002)).
} 


\section{Investment}

To be explicit about our assumptions we first deal with the continuous valuations framework in section 3.1 before we restrict ourselves to the binary case in section 3.2. We consider the binary case as a special case of the general framework that makes deriving our results much easier. But nevertheless we think that it is useful to know the implicit assumptions.

\subsection{Continuous Valuations}

The value of the item to the buyer is distributed over an interval $\left[v_{1}, v_{2}\right]$ with density $f_{b}(\cdot)$ and cumulative distribution $F_{b}(\cdot)$ and the value to the seller is distributed over an interval $\left[c_{1}, c_{2}\right]$ with density $f_{s}(\cdot)$ and cumulative distribution $F_{s}(\cdot)$. The intervals $\left[v_{1}, v_{2}\right]$ and $\left[c_{1}, c_{2}\right]$ properly overlap. We restrict the analysis to probability distributions satisfying:

$$
\begin{array}{cc}
v+\frac{F_{b}(v)-1}{f_{b}(v)} & \text { is increasing on }\left[v_{1}, v_{2}\right] \\
c+\frac{F_{s}(c)}{f_{s}(c)} & \text { is increasing on }\left[c_{1}, c_{2}\right]
\end{array}
$$

The outcome at the bargaining stage is a mechanism maximizing ex-ante expected gains from trade subject to individual-rationality constraints ${ }^{13}$ and interim incentive constraints.

Define the following functions:

$$
\begin{aligned}
X_{b}(v) \equiv \int_{c_{1}}^{c_{2}} x(v, c) f_{s}(c) d c, & X_{s}(c) \equiv \int_{v_{1}}^{v_{2}} x(v, c) f_{b}(v) d v \\
T_{b}(v) \equiv \int_{c_{1}}^{c_{2}} t(v, c) f_{s}(c) d c, & T_{s}(c) \equiv \int_{v_{1}}^{v_{2}} t(v, c) f_{b}(v) d v \\
U_{b}(v) \equiv v X_{b}(v)-T_{b}(v), & U_{s}(c) \equiv T_{s}(c)-c X_{s}(c) \\
c_{b}(v, r) \equiv v+r \underbrace{\frac{F_{b}(v)-1}{f_{b}(v)}}_{I_{b}(v)}, & c_{s}(c, r) \equiv c+r \underbrace{\frac{F_{s}(c)}{f_{s}(c)}}_{I_{s}(c)}
\end{aligned}
$$

These are the buyer's and seller's expected probability of trade, expected transfers and expected utilities from an interim perspective. $c_{b}$ and $c_{s}$ are "virtual" utilities which are crucial to derive the contraint efficient allocation. They help to define the

\footnotetext{
${ }^{13}$ Gresik (1991a) shows that restricting to ex post individual-rationality constraints is generally not associated with a loss of efficiency.
} 
following trading rule

$$
\begin{gathered}
\phi^{r}(v, c) \equiv \begin{cases}1 & \text { if } c_{b}(v, r) \geq c_{s}(c, r) \\
0 & \text { otherwise }\end{cases} \\
\text { and } \Gamma(r) \equiv \int_{c_{1}}^{c_{2}} \int_{v_{1}}^{v_{2}}\left[c_{b}(v, 1)-c_{s}(c, 1)\right] \phi^{r}(v, c) f_{b}(v) f_{s}(c) d v d c
\end{gathered}
$$

For given $r, \Gamma(r)$ equals social surplus minus "information rents".

We can state the following theorem:

\section{Theorem 1 (Myerson and Satterthwaite (1983) and Williams (1987))}

$x(\cdot)=\phi^{r}(\cdot)$ is the trading rule of an allocation, fulfilling interim-incentive and individual-rationality constraints if and only if

$$
\Gamma(r) \geq 0
$$

$U_{b}$ and $U_{s}$ can be solved in terms of $x^{*}(\cdot)=\phi^{r}(\cdot)$ :

$$
U_{b}(v)=\int_{v_{1}}^{v} X_{b}^{*}(z) d z, \quad U_{s}(c)=\int_{c_{1}}^{c} X_{s}^{*}(z) d z
$$

Expected gains from trade for the seller and the buyer under the trading rule $\phi^{r}(\cdot)$ are:

$$
U^{B}=\int_{v_{1}}^{v_{2}} U_{b}(z) f_{b}(z) d z \quad U^{S}=\int_{c_{1}}^{c_{2}} U_{s}(z) f_{s}(z) d z
$$

Therefore, the maximization problem amounts to:

$$
\begin{array}{r}
\max _{r} U^{B}+U^{S} \\
\text { subject to } \quad \Gamma(r) \geq 0
\end{array}
$$

It can be shown that $\Gamma(r)=0$ in the optimum. Having finished the recapitulation of well-known results, we can turn to the analysis of investment incentives.

Let $e^{b}$ and $e^{s}$ denote the investment levels. These actions affect the valuation of the buyer and the seller in a stochastic manner. Specifically, the cumulative distribution functions are increased or decreased in the sense of first degree stochastic dominance; 
that is

$$
\frac{\partial F_{b}\left(v \mid e^{b}\right)}{\partial e^{b}}<0 \quad \frac{\partial F_{s}\left(c \mid e^{s}\right)}{\partial e^{s}}>0
$$

We reformulate $U^{B}$ :

$$
\begin{aligned}
U^{B} & =\int_{v_{1}}^{v_{2}} X_{b}(v)\left(1-F_{b}\left(v \mid e^{b}\right)\right) d v \\
& =\int_{v_{1}}^{v_{2}} \int_{c_{1}}^{c_{2}} \phi^{r}(v, c) f_{s}\left(c \mid e^{s}\right)\left(1-F_{b}\left(v \mid e^{b}\right)\right) d v \\
& =\int_{\underline{v}\left(e^{b}, e^{s}\right)}^{v_{2}} \int_{c_{1}}^{c^{*}\left(v,\left(e^{b}, e^{s}\right)\right)} f_{s}\left(c \mid e^{s}\right)\left(1-F_{b}\left(v \mid e^{b}\right)\right) d v \\
& =\int_{\underline{v}\left(e^{b}, e^{s}\right)}^{v_{2}} F_{s}\left(c^{*}\left(v,\left(e^{b}, e^{s}\right)\right) \mid e^{s}\right)\left(1-F_{b}\left(v \mid e^{b}\right)\right) d v
\end{aligned}
$$

where $\underline{v}\left(e^{b}, e^{s}\right)$ is the smallest $v$ for which trade takes place and $c^{*}\left(v,\left(e^{b}, e^{s}\right)\right)$ is the biggest $c$ for which trade takes place if the valuation of the buyer is equal to $v$.

We can now analyze the investment incentives of both agents. Focusing on the buyer's utility is enough to assess the various distortions in the investment decision. Differentiation of $U^{B}$ with respect to $e^{b}$ and $e^{s}$ results in:

$$
\begin{aligned}
& \frac{\partial U^{B}}{\partial e^{b}}=\int_{\underline{v}\left(e^{b}, e^{s}\right)}^{v_{2}}[\underbrace{f_{s}\left(c^{*}\left(v,\left(e^{b}, e^{s}\right)\right) \mid e^{s}\right) \frac{\partial c^{*}\left(v,\left(e^{b}, e^{s}\right)\right)}{\partial e^{b}}\left(1-F_{b}\left(v \mid e^{b}\right)\right)}_{\mathbf{B H U}_{\mathbf{B}}} \\
& \underbrace{-\overbrace{F_{s}\left(c^{*}\left(v,\left(e^{b}, e^{s}\right)\right) \mid e^{s}\right)}^{>0} \overbrace{\frac{\partial F_{b}\left(v \mid e^{b}\right)}{\partial e^{b}}}^{<0}}_{\mathbf{H} \mathbf{U}_{\mathbf{B}}}] d v \\
& \frac{\partial U^{B}}{\partial e^{s}}=\int_{\underline{v}\left(e^{b}, e^{s}\right)}^{v_{2}}\left[[\underbrace{f_{s}\left(c^{*}\left(v,\left(e^{b}, e^{s}\right)\right) \mid e^{s}\right) \frac{\partial c^{*}\left(v,\left(e^{b}, e^{s}\right)\right)}{\partial e^{s}}}_{\mathbf{B H U}}+\underbrace{\frac{\partial F_{s}}{\partial e^{s}}}_{\mathbf{H} \mathbf{U}_{\mathbf{S}}}]\left(1-F_{b}\left(v \mid e^{b}\right)\right)\right] d v
\end{aligned}
$$

We can identify two determinants of investment behavior:

First we identify the (standard) externality hold-up effect. Both agents ignore benefits (and losses) they cause on their trading partners. This causes the known deviation from the maximization of the social surplus. This effect corresponds to $H U_{B}$ and $H U_{S}$ for $e^{b}$ and $e^{s}$, respectively.

Second we find the bargaining hold-up effect. Thereby changing the investment changes the bargaining outcome. In this case the buyer is held up by the seller for 
his investment because a high information rent is created ${ }^{14}$, which is taken into account in an (constrained) efficient bargaining game. This corresponds to $B H U_{B}$ and $B H U_{S}$ for $e^{b}$ and $e^{s}$, respectively. $\frac{\partial c^{*}\left(v,\left(e^{b}, e^{s}\right)\right)}{\partial e^{b}}$ and $\frac{\partial c\left(v,\left(e^{b}, e^{s}\right)\right)}{\partial e^{s}}$ stand for the changes in the allocation.

The first effect is well known from hold-up models, where the trading allocation is a fixed function maximizing (ex-post) social surplus. With asymmetric information in contrast, this effect can be retrieved only for a fixed allocation. Since the determination of this trading function is guided by a constrained maximization, the investment decisions have an impact on this function. This results in the second effect, which is new.

So investment decisions take into account two problems of "unfriendly behavior" at the bargaining stage. On the hand, each party knows that investment expenditures are sunk when bargaining starts. Thus each agent can simply say: "If you do not grant me half of the surplus, then trade with someone else". The success of such a strategy depends on the specificity of the asset ( How much it is worth to a third party) and on their bargaining power. And the crucial point is that this strategy deprives the investor of the full return to his investment.

On the other hand, the bargaining itself depends on the investment level. The intuition is as follows. Suppose first that the buyer has a high valuation. As he does not observe the cost level of the seller he states: "Let us either reach an immediate agreement and I pay you a low transfer covering your low costs or we do not sign an agreement now and let us meet again next week to resume the negotiations." By this kind of reasoning the buyer tries to avoid paying a high transfer to a seller with a low cost level. The buyer wants the seller with the low cost level to agree to an immediate exchange and thus accepting a low compensation. Since delaying trade is more harmul the higher is the surplus, a low cost seller is more anxious to reach a speedy agreement. Of course, delaying trade opportunities, which create a positive surplus, is inefficient. But this is the best the agents can achieve in view of the private knowledge of valuations.

This reasoning so far has ignored the investment level. Let us now suppose that $e^{s}$ is pretty high. Since the buyer observes this he believes that the cost level of the seller should be small. Therefore he becomes very eager to avoid paying a high transfer to the seller since the cost level is low with a high probability. In order to achieve this he will delay trade not only by one week if the seller does not accept at once but he will delay trade by one month or so. Since the buyer believes that he faces

\footnotetext{
${ }^{14}$ The information rent unambiguously increases (for a fixed allocation) if $\frac{\partial I_{b}(v)}{\partial e_{b}}<0$ or $\frac{\partial I_{s}(c)}{\partial e_{s}}<0$. Otherwise the change of the information rent is ambiguous.
} 
a low cost seller with a high probability he rather wants to make a big surplus by compensating a low cost seller than trading with a high cost seller. Due to the low probability of a low cost, the buyer does not care much about delaying trade for these types. This delay is inefficient. And as a higher investment level increases the delay further, this inefficiency becomes even worse. Of course, since we have a model with two-sided asymmetric information, the seller will argue in the same way. The outcome of this quarrel was characterized in theorem 1.

A general result for continuous valuations can be stated concerning the investment behavior of a social planer, who, of course, faces also asymmetric information at the bargaining stage. Thus a social planer can choose an optimal level of investment but has to take into account that the bargaining outcome is only constrained efficient. The following proposition serves as a benchmark for all following results about individual investment incentives. It states that the increase in inefficiency discussed above does not outweigh the gain from having higher values or lower costs with a higher probability . But we will show that this is not true for the individual utility.

The optimal allocation $\phi^{r}$ depends on the investment level among other things also via the function $r$. But note that in general it is not true that $r()$ is increasing in

$e^{b}$ or $e^{s}$. Thus, even if one makes the assumption that $\frac{\partial I_{b}(v)}{\partial e_{b}}<0$, the sign of $c^{*}()$ cannot be determined. The "efficiency of the allocation" can be improved despite a higher information rent $(r()$ can decrease).

\section{Proposition 1}

The value of $U^{B}+U^{S}$ is enhanced both by a higher $e^{b}$ and a higher $e^{s}$.

Thus in a cooperative world the agents would agree, for most cost-functions, to a pair of positive investment-levels. But it will be shown that this is not the case in a world with uncooperative behavior, which is, at least in hold-up models, the prevailing one. By definition, the incentives for selfish investment by the buyer and cooperative investment of the seller add up to the optimal level of $e^{b}$. And likewise for $e^{s}$. Therefore cooperative over-investment corresponds to no incentives for selfish investment and vice versa. This, among other things, will be laid out in the next section for a setting with two types. This framework, although a priori restrictive, provides all the intuition. The important implicit assumption we make in the discrete setting is that $r(\cdot, \cdot)$ increases with higher investment. In particular, it is (implicitly)

assumed that $\frac{\partial I_{b}\left(v, e^{b}\right)}{\partial e^{b}}<0$ and $\frac{\partial I_{s}\left(c, e^{s}\right)}{\partial e^{s}}>0$. Thus, although the general validity of the results is restricted, focusing on a discrete setting makes all points. By considering two types we restrict ourselves to the interesting case where a higher investment 
level creates a lot of delay in the bargaining process and thus the bargaining holdup effect is most impressive. We start in section 3.2 with independently distributed types and allow for correlation in section 3.3.

\subsection{Two Types}

The agents' valuations/types $\theta_{i}, i \in\{B, S\}$ are drawn from a common knowledge distribution on $\left\{B_{H}, B_{L}\right\} \times\left\{S_{H}, S_{L}\right\}\left(B_{H}-B_{L}>0, S_{H}-S_{L}>0\right)$. In this setting the trading rule $x(\cdot)$ is a function from $\left\{B_{H}, B_{L}\right\} \times\left\{S_{H}, S_{L}\right\}$ into $[0,1]$ and the payment rule $t(\cdot)$ is a function from $\left\{B_{H}, B_{L}\right\} \times\left\{S_{H}, S_{L}\right\}$ into $\mathbb{R}$. The marginal distribution is given by $p\left(S_{H}\right)=(1-\epsilon), p\left(S_{L}\right)=\epsilon, p\left(B_{H}\right)=\delta, p\left(B_{L}\right)=(1-\delta)$ and thus the overall distribution is determined. In the main text we denote for $M, N \in\{H, L\}$ $x_{N}^{M}=x\left(B_{M}, S_{N}\right)$ and $t_{N}^{M}=t\left(B_{M}, S_{N}\right)$ Investment is modeled as an increase in $\delta$ or $\epsilon$.

The agents agree to participate if their ex-post individual-rationality constraint is satisfied. This can be dispensed with in the independent case, but is an essential ingredient for the case with correlation. The outcome of bargaining still maximizes total gains from trade, so the agents choose the mechanism $M=\{x(\cdot), t(\cdot)\}$ to maximize the expectation of $U(B)+U(S)$ subject to incentive and interim individualrationality constraints.

The derivation of the outcome is similar to the continuous case. The agents always trade in state $\left(B_{H}, S_{L}\right)$ and never trade in state $\left(B_{L}, S_{H}\right)$. Trading in states $\left(B_{H}, S_{H}\right)$ and $\left(B_{L}, S_{L}\right)$ is desirable, but efficiency is prevented by asymmetric information and individual-rationality constraints. It turns out that only $x_{H}^{H}$ or $x_{L}^{L}$ equals one in the optimal allocation. Since both cases are symmetric we focus on the case where $x_{H}^{H}=1$. In the appendix we provide a necessary and sufficient assumption to ensure that such an outcome is indeed optimal and characterize the optimal mechanism (Assumption A and proposition A).

This results in the following ex ante expected utility as a function of investment decisions $\epsilon$ and $\delta$.

$$
\begin{aligned}
E(U(B)) & =\delta \epsilon\left(B_{H}-B_{L}\right) x_{L}^{L}(\epsilon, \delta) \\
E(U(S)) & =\delta \epsilon\left(S_{H}-S_{L}\right) x_{H}^{H}=\delta \epsilon\left(S_{H}-S_{L}\right)
\end{aligned}
$$

Now the investment incentives for the buyer and the seller can be analyzed. Thereby two cases are distinguished (cp. e.g. Che and Hausch (1999)) : Self-investment and cooperative investment. No intermediate cases will be considered. This means either 
both agents invest in their own valuations or both invest in the valuations of their potential trading partner. As indicated above we deal only with $x_{H}^{H}=1$ and so assume that a change in investments do not change the optimality of choosing $x_{H}^{H}=$ 1.

As a benchmark we define the following investment levels :

$\epsilon^{*}, \delta^{*}$ maximize ex-ante expected gains of trade

(bargaining with symmetric information) :

$\epsilon^{*}, \delta^{*} \in \operatorname{argmax}_{\epsilon, \delta} \quad \epsilon \delta\left(B_{H}-S_{L}\right)+\delta(1-\epsilon)\left(B_{H}-S_{H}\right)+(1-\delta) \epsilon\left(B_{L}-S_{L}\right)-c(\epsilon)-k(\delta)$

$\epsilon_{\text {asym }}^{*}, \delta_{\text {asym }}^{*}$ maximize ex-ante expected gains of trade with asymmetric

information (bargaining with asymmetric information) :

$$
\epsilon_{\text {asym }}^{*}, \delta_{\text {asym }}^{*} \in \operatorname{argmax}_{\epsilon, \delta} \quad \epsilon \delta\left\{\left(S_{H}-S_{L}\right)+\left(B_{H}-B_{L}\right) x_{L}^{L}\right\}-c(\epsilon)-k(\delta)
$$

where $c(\epsilon)$ and $k(\delta)$ are cost functions.

The following table describes the private incentives to invest and the externality on the trading partner (bargaining with asymmetric information). Each entry has the form \begin{tabular}{|c|}
\hline Private Incentive \\
\cline { 3 - 3 } Externality
\end{tabular} negative (-), zero (0) or ambiguous(?).

\begin{tabular}{|c||c||c|}
\hline & Buyer & Seller \\
\hline \multirow{2}{*}{$\begin{array}{c}\text { Self- } \\
\text { investment }\end{array}$} & $?$ & + \\
\cline { 2 - 3 } & + & 0 \\
\hline \hline $\begin{array}{c}\text { Cooperative } \\
\text { investment }\end{array}$ & 0 & + \\
\cline { 2 - 3 } & + & $?$ \\
\hline
\end{tabular}

The correctness of this table can easily be seen from calculating derivatives of the expected utility functions. Notice the symmetry of the entries. For clarification of the incentives the buyer is faced with, we describe the effects of $\epsilon$ and $\delta$ on $E(U(B))$ (the effects on $E(U(S))$ are obvious since $x_{H}^{H}=1$ ) and relate them to the continuous-type formulation. Recall that

$$
E(U(B))=\delta \epsilon\left(B_{H}-B_{L}\right) x_{L}^{L}(\epsilon, \delta)
$$

We can retrieve the two effects identified as driving investment behaviour in the continuous case. First, the externality hold-up effect describes the investment incentives for a fixed trading rule and so corresponds to the maximization of $\delta \epsilon\left(B_{H}-B_{L}\right) x$ for 
a fixed trading decision $x$. The investment incentives caused by a change of $x_{L}^{L}(\epsilon, \delta)$ were named bargaining hold-up effect.

We can now state our two main results. The opposing effects identified with continuous valuations lead to results which are in contrast to all results which have been established so far in the literature. First consider the buyer, deciding about how much to invest in his own valuation. On the one hand it is possible that the buyer does not invest at all and on the other hand the buyer may invest more than is efficient. Second, the seller's incentives to invest in the buyer's valuation can be higher than the efficient level as well. Thus the seller may cooperatively overinvest. The roles switch if $x_{L}^{L}=1$ is an optimal choice at the bargaining stage.

Proposition 2 Both selfish and cooperative overinvestment can be possible.

Both selfish and cooperative investment incentives can be negative.

A complete description of the various distortions are given in proposition $\mathrm{B}$ in the appendix.

Concerning the cooperative investment of the seller, no clear statement, contrary to the suggestion of the literature, can be made. A statement claiming that selfinvestment is more intense than cooperative investment cannot be supported in this setting. This point will become even stronger in the following section. Notice that investment incentives can be zero. Thus, the bargaining hold-up effect can deteriorate the bargaining power to a level, as if the bargaining power was negative. This means that the agents' individual utilities can be decreasing in their own investment level.

\subsection{Correlated Types}

In this section, and only in this section, we relax the assumption of independently distributed valuations and allow for correlation. This stresses again the impact that the bargaining hold-up effect exerts on the investment decisions. Indeed, for a fixed allocation $x(\cdot)$ and transfer $t(\cdot)$, thus independent of the investments, the correlation between valuations and costs does not matter. It is only the probability of a specific cost level and the way in which it is shifted by investing that matters. In particular, the degree of correlation is irrelevant in hold-up models with Nash-bargaining. To highlight this we show that this effect can even result in simultaneous cooperative overinvestment.

To model dependently distributed valuations we stay in line with Myerson (1981), 
Cremer and McLean (1985), Cremer and McLean (1988) and McAfee and Reny (1992), who assume that agents' willingness to pay is generated from some common known prior, and agents' beliefs are obtained by conditioning this common prior on the agents' private information. This is in contrast to Neeman (2000), who relaxes the assumption that agents' beliefs determine their willingness to pay. The following table describes the probability measure. The entries are the joint and marginal probabilities, respectively ${ }^{15}$.

\begin{tabular}{|c|c|c|c|}
\hline$p(B, S)$ & $S_{H}$ & $S_{L}$ & $\begin{array}{c}\text { marginal } \\
\text { distribution of } B\end{array}$ \\
\hline$B_{H}$ & $\alpha_{1} q$ & $q$ & $q\left(1+\alpha_{1}\right)$ \\
\hline$B_{L}$ & $1-\left(1+\alpha_{1}+\alpha_{2}\right) q$ & $\alpha_{2} q$ & $1-\left(1+\alpha_{1}\right) q$ \\
\hline $\begin{array}{c}\text { marginal } \\
\text { distribution of } S\end{array}$ & $1-\left(1+\alpha_{2}\right) q$ & $q\left(1+\alpha_{2}\right)$ & \\
\hline
\end{tabular}

The covariance of this distribution is equal to

$$
\left[q\left(1+\alpha_{1}\right)\left(1+\alpha_{2}\right)-1\right]\left\{\left(B_{H}-B_{L}\right)\left(S_{H}-S_{L}\right)\right\}
$$

Let us first characterize the outcome of bargaining. This means the maximum of the ex-ante expected gains from trade. The outcome is similar to the one with independently distributed types. The agents always trade in state $\left(B_{H}, S_{L}\right)$ and never trade in state $\left(B_{L}, S_{H}\right)$. Again only $x_{H}^{H}$ or $x_{L}^{L}$ equals one in the optimal allocation and thus we focus again on the case where $x_{H}^{H}=1$. In the appendix we provide a necessary and sufficient assumption to ensure that such an outcome is indeed optimal and characterize the optimal mechanism (Assumption B and proposition C, D), which maximizes the expectation of $U(B)+U(S)$ subject to incentive constraints.

This results in the following ex-ante expected utility :

$$
\begin{aligned}
E(U(B)) & =q \cdot x_{L}^{L} \cdot\left(B_{H}-B_{L}\right) \\
E(U(S)) & =q \cdot x_{H}^{H} \cdot\left(S_{H}-S_{L}\right)
\end{aligned}
$$

As in the case of independent valuations, the investment incentives for the buyer and the seller can be analyzed. But there is an important difference concerning the direction of investment. In the case of independently distributed valuations we have

\footnotetext{
${ }^{15}$ As a matter of course this involves restrictions on the parameters.
} 
distinguished between self-investment and cooperative investment. This distinction will be maintained, but by increasing e.g. the probability of $B_{H}$, the correlation between $B$ and $S$ can change and thus a shift in the information rents is induced. This in turn has important consequences for the efficiency of trade and the investment incentives at the ex ante stage. For clarification and comparison, we give the same decomposition of $E(U(B))$ as with independent valuations.

$$
E(U(B))=\left(B_{H}-B_{L}\right) \overbrace{q\left(1+\alpha_{1}\right)}^{P\left(B_{H}\right)} \underbrace{\frac{1}{1+\alpha_{1}}}_{p\left(S_{L} \mid B_{H}\right)} x_{L}^{L}
$$

The same interpretations as given above apply, but with dependent valuations three parameters can be manipulated. This gives, for example, the possibility of decreasing $p\left(S_{L} \mid B_{H}\right)=\frac{1}{1+\alpha_{1}}$ (corresponds to a decrease of $\epsilon$ with independent valuations) and of increasing $P\left(S_{L}\right)=q\left(1+\alpha_{2}\right)$ (corresponds to an increase of $\epsilon$ with independent valuations), which is obviously not feasible with independent valuations. In particular, (expected) information rents/ conditional probabilities and marginal probabilities can be widely changed independently of one another.

This motivates the subsequent definition of investment in $B$ respectively $S$. This is one way of doing this which proves our point.

Investment in $B$ :

It is a minimal requirement for an investment in $B$ that the (marginal) probability $q\left(1+\alpha_{1}\right)$ of $B_{H}$ is increased (and thus the marginal probability $\left(1-\left(1+\alpha_{1}\right) q\right)$ of $B_{L}$ is decreased) and the marginal probability $q\left(1+\alpha_{2}\right)$ of $S_{L}$ and $1-\left(q\left(1+\alpha_{2}\right)\right)$ of $S_{H}$ are unchanged. We parameterize the investment through $\delta$. It has the following effects on the three parameters determining the probability distribution.

$$
\hat{\delta}=\left\{\begin{aligned}
q \rightarrow q+\delta \\
\alpha_{2} \rightarrow \frac{q \alpha_{2}-\delta}{q+\delta} \\
\alpha_{1} \rightarrow \alpha_{1}
\end{aligned}\right.
$$

for $q, \alpha_{1}, \alpha_{2}, \delta$ inducing an inefficient outcome, Case $H$ and a probability measure. Note that $q$ is increased, $\alpha_{2}$ is decreased and $\alpha_{1}$ and $q\left(1+\alpha_{2}\right)$ are constant. Furthermore, a higher $\delta$ results in a lower $x_{L}^{L}$, i.e. $\frac{\partial x_{L}^{L}}{\partial \delta}<0$.

Investment in $S$ :

We require an investment in $S$ to increase the (marginal) probability $q\left(1+\alpha_{2}\right)$ of $S_{L}$ and to leave the marginal probability $q\left(1+\alpha_{1}\right)$ of $B_{H}$ unchanged. We parameterize the investment through $\epsilon$. It has the following effects on the three parameters 
determining the probability distribution.

$$
\hat{\epsilon}=\left\{\begin{array}{c}
q \rightarrow q-\epsilon \\
\alpha_{2} \rightarrow \frac{q \alpha_{2}+2 \epsilon}{q-\epsilon} \\
\alpha_{1} \rightarrow \frac{\alpha_{1} q+\epsilon}{q-\epsilon}
\end{array}\right.
$$

for $q, \alpha_{1}, \alpha_{2}, \epsilon$ inducing an inefficient outcome, Case $H$ and a probability measure. Note that $q$ is decreased, $\alpha_{2}$ and $\alpha_{1}$ are increased and $q\left(1+\alpha_{1}\right)$ is constant. Furthermore, a higher $\delta$ results in a higher $x_{L}^{L}$, i.e. $\frac{\partial x_{L}^{L}}{\partial \delta}>0$ because $q \alpha_{2}$ is increased. The impact of a higher investment level is due to the same reflections of the agents as in section 3.2. In delaying trade (between $B_{L}$ and $S_{L}$ ) the agents trade-off the probability of foregoing surplus $\left(\alpha_{2} \cdot q\right)$ and the probability that they face a "good type" and leave too much surplus to him $(q)$. Thus the agents face the same tradeoff as with independently distributed valuations. But in this latter case an increase of $P\left(S_{L}\right)(=\epsilon)$ implies an increase in $P\left(B_{H}, S_{L}\right)(=\delta \cdot \epsilon)$ what is not true in this section. Different "types" of the buyer have different beliefs about the cost of the seller and these beliefs are not invariant to investment both in $B$ and in $S$. And different beliefs result in a different assessment of the above trade-off by the agents. This in turn changes the bargaining outcome. Thus the way investment can affect bargaining becomes broader. This means the bargaining hold-up effect will have a higher weight in the considerations of the agents. So it is the interaction of the bargaining hold-up effect and the correlation which renders the analysis of investment incentives in this section worthwhile.

To analyze the various distortions let us define as a benchmark the following investment levels :

$\epsilon^{*}, \delta^{*}$ maximize ex-ante expected gains of trade $(W)$ (bargaining with symmetric information):

$$
\epsilon^{*}, \delta^{*} \in \operatorname{argmax}_{\epsilon, \delta} \quad W:=q\left(B_{H}-S_{L}\right)+\alpha_{1} q\left(B_{H}-S_{H}\right)+\alpha_{2} q\left(B_{L}-S_{L}\right)-c(\epsilon)-k(\delta)
$$

$\epsilon_{\text {asym }}^{*}, \delta_{\text {asym }}^{*}$ maximize ex-ante expected gains of trade with asymmetric information (bargaining with asymmetric information) :

$$
\epsilon_{\text {asym }}^{*}, \delta_{\text {asym }}^{*} \in \operatorname{argmax}_{\epsilon, \delta} \quad W_{\text {asym }}:=q x_{L}^{L}\left(B_{H}-B_{L}\right)+q x_{H}^{H}\left(S_{H}-S_{L}\right)
$$

with $q, \alpha_{1}, \alpha_{2}$ depending on $\epsilon$ and $\delta$ as defined above.

The main point of this section is stated by the following proposition, which compares 
private incentives to the benchmark cases. It states that simultaneous cooperative overinvestment is possible, whereas no incentives for selfish investment exist. In our view this is the strongest claim which can be made against the emerging consensus in the literature (see e.g. Che and Hausch (1999) and Edlin and Hermalin (1998)).

Proposition 3 Simultaneous cooperative overinvestment is possible. Simultaneous negative incentives for selfish investment are possible.

A complete characterization of investment incentives is again delegated to the appendix.

In summary, we have achieved, by a thoughtful choice of the investment function, that the interaction of (the change in) correlation and the bargaining hold-up effect a result in diametrical opposition to the literature, namely (joint) cooperative overinvestment.

\section{$4 \quad$ Property Rights}

\subsection{The model}

In this section we want to emphasize the relevance of the assignment of property rights. Except for section 4.4 we only deal with the assignment of property rights and ignore relationship specific investment. The timing is then as follows. The agents agree on an assignment of ownership at date $t_{0}$. The rest remains unchanged.

To give a role to property rights, we first have to introduce inside options ${ }^{16}(>0)$ into the model. Property rights then determine to what degree these can be exercised. Thus ownership corresponds to self-consumption of the asset. This assignment arises whenever trade does not take place between the buyer and the seller. Therefore the interim utility increases by $\{(1-X(B, S)) \times$ (inside option) $\}$ (see below for a more formal description). We give the following interpretation of this definition.

Therefore we extend the one given in section 2 , where $x(B, S):=\exp (-r \tau(B, S))$ is interpreted as reaching agreement at time $\tau(B, S)$. An inside option of amount $k$ gives utility of $k$ if it is exercised from date 0 to $\infty$. Because usage of this option

\footnotetext{
${ }^{16}$ Considering outside options instead of inside options (implicitly) assumes that trade can be stopped permanently and irreversibly by trading with a third party (see below). Outside options refer to the payoffs that bargainers obtain by quitting the negotiation permanently. Inside options refer to the payoff that bargainers obtain until an agreement is reached. For a discussion of inside options and outside options see e.g. (38, Muthoo (1999)).
} 
ends when an agreement is reached (at date $\tau$ ), the expected utility (at date 0 ) from the inside option amounts to $k *(1-\exp (-r \tau))$

There is a crucial difference between assigning ownership to increase the inside option and stipulating a high outside option in a contract. Since trade does not necessarily take place immediately, agents benefit from the right to make use of the asset until an agreement is reached. A contract would only change the agents' bargaining power and thus would decrease welfare from an ex-ante point of view. Deviating from the null-contract is thus detrimental to welfare.

Ownership is defined as the possession of residual control rights of assets. It remains important as long as no trade has taken place. In particular, if trade never takes place ( $\tau=\infty$ in the interpretation given above) this determines the inside(outside) utility. As in Hart (1995), this is in contrast to the more standard definition, whereby an owner possesses the residual income from an asset. The latter is not observable so that a discussion of bundling together residual income and residual control is not necessary. The sole direct effect of controlling assets is on inside opportunity, which emerges whenever trade has not yet taken place. The consequences of different assignments of property/control rights on the bargaining outcome and on the (ex-ante) investment incentives will be discussed in this section. In a complete contract framework, asset usage is dependent on the state of the world (in an ex-ante contract). In an incomplete contract framework this dependency is (exogenously) restricted. The owner of residual control rights decides about the usage of the assets in all contractually unspecified states of the world/contingencies. The restricted dependency makes this ownership powerful. In addition, Hart assumes that the owner of residual rights of control automatically has all control rights on the asset, e.g. because of high cost of specification. This means that asset usage is (ex-ante) completely state independent. With incomplete information, asset usage cannot (by definition) be dependent on the state of the world, but has to be determined as part of the allocation of a mechanism. According to the distinction between a complete contract and an (totally) incomplete contract framework, we distinguish between long-term property and short-term property:

In the case of long-term property the same restrictions on asset usage as in Hart (1995) are imposed. In short, ownership is state independent, or rather, ownership is assigned before bargaining starts and cannot be changed in the meantime. In macroeconomic terms, asssignment of ownership is rigid in comparison to trading decisions (e.g. because of higher costs). In game theoretic or contract theoretic terminology this amounts to the assumption of renegotiation-proof property-rights.

We briefly examine this point relating it to the discussion of Hart and Moore (1999) 
and Maskin and Tirole (1999a,b). A main topic of their discussion is the question of whether commitment, in particular whether no renegotiation, is possible. Maskin and Tirole (MT) argue that in an ideal world the buyer and the seller could register their contract with the court, and could instruct the court to enforce the first contract and ignore any revised contract. Hart and Moore (HM) reply that such an arrangement could be circumvented by operating through a middleman. Moreover, a system like this does not exist anywhere and would require a system-wide institutional change. We argue that this criticism of MT's proposal can be weakened in the case of property rights. We interpret the arrangement of land registers as a registration system propagated by MT. On the one hand, such a system exists and thus does not require a huge institutional change. On the other hand, contracts circumventing agreements enshrined in the land register are null and void. Commercial registers help to prevent the possibility of transferring decision rights instead of property rights to a third person. For example, the confidential clerks must be itemized in the commercial register and there is a certain degree of freedom to add further information. With the support of these registers preventing renegotiation should be much easier. ${ }^{17}$ Alternatively, one could add further informational asymmetries concerning the value of being the owner of the assets to prevent renegotiation ${ }^{18}$.

Short-term property, by contrast, means that ownership is fully state-dependent. Because of private information its assignment depends on the announced state(type) in a direct mechanism ${ }^{19}$. In the light of the discussion with complete information we concentrate on these two extreme specifications, namely full state dependency and state independency. First we deal with long-term property. Afterwards short-term property and the interplay between assignment of property and investment decisions are considered.

\section{$4.2 \quad$ Long-term property}

Like Hart (1995) we focus on a highly stylized situation in which there are just two assets, $a 1$ and $a 2$, as well as the buyer and the supplier operating them. The seller, in combination with $a 2$, supplies a widget to the buyer. The buyer, in combination with $a 1$ uses this widget to produce output that is sold on the output market or used

\footnotetext{
${ }^{17}$ As an extreme example consider a testation which states that a firm has to be kept in the possession of a specific family. This makes conferring authority to a manager or a CEO much more difficult. This is reinforced if permanent membership in the supervisory board is granted.

${ }^{18}$ Hart and Moore (1998) use asymmetric information to prevent renegotiation ex-post, making use of the results of Mailath and Postlewaite (1990) and Rob (1989).

${ }^{19}$ By the revelation principle, restricting to direct mechanism is wlog.
} 
by himself. Postponing investment considerations, we are left with the bargaining problem.

To be more precise, the (interim) utility of the buyer with valuation $B$ and inside option $v(B)$ and of the seller with cost $S$ and inside option $v(S)$ is defined as:

$$
\begin{aligned}
& U(B)=B X(B)-T(B)+(1-X(B)) v(B) \\
& U(S)=T(S)-S X(S)+(1-X(S)) v(S)
\end{aligned}
$$

where capital letters denote expected trade or transfer for the buyer of type $B$ or the seller of type $S$. In this and all subsequent sections we again assume independently distributed signals.

The interim individual-rationality constraints change to

$$
\begin{aligned}
& U(B) \geq v(B) \\
& U(S) \geq v(S)
\end{aligned}
$$

The inside option $v(\cdot)$ is realized by delaying trade forever.

In the same way as Hart (1995) we focus on three "leading" ownership structures:

Non-integration: buyer owns a1 and seller owns a2

Buyer-integration: buyer owns a1 and a2

Seller-integration: $\quad$ seller owns a1 and a2

We focus on the case where assets are strictly complementary assets, this means we assume that access to one asset alone has no effect on the inside options. Assigning ownership has the following effect on the inside option. In case of buyer-integration $v(B)=c>0$ and in case of seller-integration $v(S)=c>0$. In all other cases $v(S)$ and $v(B)$ are assumed to equal zero. Type-dependent inside options can be added by defining $v\left(S_{L}\right)=\alpha v\left(S_{H}\right)=v(S)$ and $v\left(B_{H}\right)=\alpha v\left(B_{L}\right)=v(B)$ for some $\alpha>1$. The crucial impact of a reallocation of property rights is the change in the inside option caused through integration or non-integration.

First we have to analyze the bargaining outcome. One important difference is the change of information rents because of different inside options. This point is clarified 
by means of the situation of the buyer:

$$
\begin{aligned}
U\left(B_{H}\right) & =B_{H} X\left(B_{H}\right)-T\left(B_{H}\right)+\left(1-X\left(B_{H}\right)\right) v\left(B_{H}\right) \\
& =B_{H} X\left(B_{L}\right)-T\left(B_{L}\right)+\left(1-X\left(B_{L}\right)\right) v\left(B_{H}\right) \\
& =\left(B_{H}-B_{L}\right) X\left(B_{L}\right)+\underbrace{\left(1-X\left(B_{L}\right)\right)\left(v\left(B_{H}\right)-v\left(B_{L}\right)\right)}_{B_{H} \text { 's Autarkic Rent }}+v\left(B_{L}\right)
\end{aligned}
$$

To understand this, recall the reasoning of the seller. He proposes to the buyer to either buy the good immediately for a high price or to wait and then get the object for a lower price. Since waiting is more costly for the buyer with a high valuation, the high "type" agrees to pay the high price whereas the low "type" waits to pay a low price. If now the inside option of the high "type" increases by more than that of the low "type", due to a shift of ownership from non-integration to buyer-integration, delay for the high value buyer becomes less costly. Buyer-integration allows him to use the asset while bargaining is delayed. Therefore the seller has to revise his offer and decrease the price he wants the high "type" to accept and pay immediately. Of course $U\left(B_{H}\right)$ can be expressed as

$$
U\left(B_{H}\right)=\left(\left(B_{H}-v\left(B_{H}\right)\right)-\left(B_{L}-v\left(B_{L}\right)\right)\right) X\left(B_{L}\right)+v\left(B_{H}\right)
$$

The information rent $U\left(B_{H}\right)-v\left(B_{H}\right)$ decreases if $v\left(B_{H}\right)-v\left(B_{L}\right)$ increases. But note that for fixed $X\left(B_{L}\right), U\left(B_{H}\right)$ increases if $v\left(B_{H}\right)-v\left(B_{L}\right)$ increases even if $B_{H}$ 's individual-rationality constraint is non-binding. This is exactly what equation 2 states and what was explained afterwards.

The rest of the analysis resembles that of the preceding sections, so a characterization of the bargaining outcome is again delegated to the appendix.

Reallocating ownership has several effects on the outcome.

1. A higher inside option increases utility in the case of a delay of trade. This is positive.

2. The need to reach an agreement becomes less urgent. This is negative but outweighed by the positive first effect.

3. The price to be paid by $B_{L}$ (in case of buyer-integration) after a delay must decrease since otherwise $B_{L}$ would prefer to exercise his inside option. This again makes it necessary to decrease the price demanded from $B_{H}$ since otherwise he would prefer to wait, exercising his inside option, and then trade 
for a lower price. To avoid this, trade with $B_{L}$ is delayed further und thus inefficiency increases. This again is negative.

4. If the inside option of the high "type" increases by more than that of the low "type", delay for the high value buyer becomes less costly. Therefore the seller delays trade with the low "type" further, in order to avoid at least partially a downward revision of his offer. This again is negative.

All but the first effect are negative since they increase delay (decrease $x_{L}^{L}$ ). Thus the assignment of property rights has an influence on the gains from trade. This is in contrast to most known models (see Holmstrom and Roberts (1998)). Furthermore the absolute value (of asset specificity) has an influence on the allocation. The reason is again the bargaining hold-up effect. The lower is the value of the inside option (the higher is asset specificity) the higher will be the costs of delay and the higher is the agents' eagerness to reach an agreement ${ }^{20}$.

The agents agree on the allocation, maximizing the sum of their (ex ante) expected utilities $U:=E(U(B))+E(U(S))$. $U$ equals the sum of gains from trade (between these two parties) and the gains from exercising inside options. We discuss the effects of different assignments of property on $U$ for two cases:

$I$ : Compare Non-integration $(v(S)=v(B)=0)$ and Buyer-integration $(v(S)=$ $0, v(B)>0)$.

$I I \quad$ : Compare Buyer-integration $(v(S)=0, v(B)>0)$ and Sellerintegration $(v(S)>0, v(B)=0)$.

We start with Case $I$ :

The objective funtion $U$ is:

$$
\begin{array}{r}
U=\delta \epsilon\left(B_{H}-S_{L}\right)+\delta(1-\epsilon)\left(B_{H}-S_{H}\right)+(1-\delta) \epsilon\left(B_{L}-S_{L}\right) x_{L}^{L} \\
+(1-\delta)\left(1-\epsilon x_{L}^{L}\right) v\left(B_{L}\right)
\end{array}
$$

Differentiating with respect to $k:=v\left(B_{L}\right)\left(v\left(B_{H}\right):=\alpha k\right)$ results in:

$$
\begin{aligned}
\frac{\partial U}{\partial k} & =(1-\delta) \epsilon\left(B_{L}-S_{L}\right) \frac{\partial x_{L}^{L}}{\partial k}+(1-\delta)\left[\left(1-\epsilon x_{L}^{L}\right)-\epsilon v\left(B_{L}\right) \frac{\partial x_{L}^{L}}{\partial k}\right] \\
& =\underbrace{\frac{\partial x_{L}^{L}}{\partial k}(1-\delta) \epsilon\left[\left(B_{L}-S_{L}\right)-v\left(B_{L}\right)\right]}_{\rho}+\underbrace{(1-\delta)\left(1-\epsilon x_{L}^{L}\right)}_{\sigma}
\end{aligned}
$$

\footnotetext{
${ }^{20}$ Matouschek(2002) also identifies a trade-off between increasing the benefits during delay and decreasing delay itself. As he restricts himself to type-independent inside options, his analysis of the consequences of reallocating property rights is less detailed.
} 
where

$$
\frac{\partial x_{L}^{L}}{\partial k}=\frac{1}{D}\left(x_{L}^{L} \epsilon(\alpha \delta-1)-\alpha \delta\right)<0 \quad \text { with } x_{L}^{L}=\frac{N}{D}
$$

Thus a higher degree of buyer integration has an unambiguously negative impact on trading. This is due to an increase in information rents and a lower value of trade. The value of trading is lower the smaller is the gap between the surplus from trading and the surplus from exercising the inside option.

The two terms $\rho$ and $\sigma$ have the following interpretations:

As $x_{L}^{L}$ is decreasing in $k$ (delaying trade becomes less expensive), $\rho$ is the loss inflicted by a lower $x_{L}^{L}$. This loss is proportional to the difference between gains from trade and the inside option. This favors non-integration over buyer-integration.

Term $\sigma$ is the gain from receiving $k$ in the event of no trade. This happens with probability $(1-\delta)\left(1-\epsilon x_{L}^{L}\right)$. This means that a lower probability of trade for $B_{L}$ makes this effect stronger. This favors buyer-integration over non-integration. For a given delay in trade, it is not efficient to let the assets unused. But as just noted, a higher utility while bargaining increases delay, i.e. increases inefficiency.

More generally, one can say that a higher inside option increases gains from no trade but hampers trade. Both effects can be dominating. This is sumarized in the following proposition.

Proposition 4 A decision between non-integration and buyer-integration has no clear-cut result. Either of these forms of integration can dominate the other. This depends on the comparison of the magnitudes of the (windfall) gain from a higher inside option in the case of no trade (effect $\sigma$ ) to the loss incurred by a lower probability of trade $x_{L}^{L}$ (effect $\rho$ ).

A comparison becomes simpler if one assumes that the inside options are type independcent, this means $v\left(B_{H}\right)=v\left(B_{L}\right)$ and $v\left(S_{L}\right)=v\left(S_{H}\right)$. In this case $U$ is a convex function in $k$. This means that either $k=0$ or the maximal feasible $k$ is optimal ${ }^{21}$. To see the convexity, note that

$$
\frac{\partial^{2} U}{\partial^{2} k}=\frac{\partial^{2} x_{L}^{L}}{\partial^{2} k}(1-\delta) \epsilon\left[\left(B_{L}-S_{L}\right)-v\left(B_{L}\right)\right]-2(1-\delta) \epsilon \frac{\partial x_{L}^{L}}{\partial k}
$$

\footnotetext{
${ }^{21}$ Matouschek (2002) claims that this result (his main result) also holds for arbitrary continuous valuations. But his proof seems to be inconclusive to me. The optimal solution is of course a corner solution since for all valuations either $q=0$ or $q=1$. In my view, his arguments do not imply that the assignment of property rights is also a corner solution ( $k=0$ or $k$ maximal), although the results sounds intuitive and interesting. At least the results hold in the binary case.
} 
and

$$
\frac{\partial^{2} x_{L}^{L}}{\partial^{2} k}=\frac{-2}{D} \frac{\partial x_{L}^{L}}{\partial k} \epsilon(1-\delta)>0
$$

Case $I I$ :

With seller-integration the objective funtion $U=U^{S}$ is:

$$
\begin{aligned}
U^{S} & =\delta \epsilon\left(B_{H}-S_{L}\right)+\delta(1-\epsilon)\left(B_{H}-S_{H}\right)+(1-\delta) \epsilon\left(B_{L}-S_{L}\right) x^{S}\left(B_{L}, S_{L}\right) \\
& +\epsilon(1-\delta)\left(1-x^{S}\left(B_{L}, S_{L}\right)\right) v\left(S_{L}\right)+(1-\epsilon)(1-\delta) v\left(S_{H}\right)
\end{aligned}
$$

With buyer-integration the objective funtion $U=U^{B}$ is:

$$
\begin{aligned}
U^{B} & =\delta \epsilon\left(B_{H}-S_{L}\right)+\delta(1-\epsilon)\left(B_{H}-S_{H}\right)+(1-\delta) \epsilon\left(B_{L}-S_{L}\right) x^{B}\left(B_{L}, S_{L}\right) \\
& +(1-\delta)\left(1-\epsilon x^{B}\left(B_{L}, S_{L}\right)\right) v\left(B_{L}\right)
\end{aligned}
$$

If $v\left(B_{L}\right)=v\left(B_{H}\right)=v\left(S_{L}\right)=v\left(S_{H}\right)$ then $x^{S}=x^{B}$ and $U^{S}=U^{B}$. Thus, the agents are indifferent between seller and buyer integration. Therefore, we concentrate on type-dependent inside options $\left(v\left(S_{L}\right)=\alpha v\left(S_{H}\right)>0, v\left(B_{H}\right)=\alpha v\left(B_{L}\right)>0\right)$. Differentiating with respect to $\alpha^{S}\left(=v\left(S_{L}\right) / v\left(S_{H}\right)\right)$ results in:

$\frac{\partial U^{S}}{\partial \alpha^{S}}=\underbrace{\frac{\partial x^{S}\left(B_{L}, S_{L}\right)}{\partial \alpha^{S}}(1-\delta) \epsilon\left[\left(B_{L}-S_{L}\right)-v\left(S_{L}\right)\right]}_{\rho^{S}}+\underbrace{(1-\delta) \epsilon\left(1-x^{S}\left(B_{L}, S_{L}\right)\right) v\left(S_{H}\right)}_{\sigma^{S}}$

where

$$
\frac{\partial x^{S}\left(B_{L}, S_{L}\right)}{\partial \alpha^{S}}=\frac{-(1-\delta) \epsilon v\left(S_{H}\right) x^{S}\left(B_{L}, S_{L}\right)}{D^{S}}<0 \quad \text { with } x^{S}\left(B_{L}, S_{L}\right)=\frac{N^{S}}{D^{S}}
$$

Differentiating with respect to $\alpha^{B}\left(=v\left(B_{H}\right) / v\left(B_{L}\right)\right)$ results in:

$$
\frac{\partial U^{B}}{\partial \alpha^{B}}=\underbrace{\frac{\partial x^{S}\left(B_{L}, S_{L}\right)}{\partial \alpha^{B}}(1-\delta) \epsilon\left[\left(B_{L}-S_{L}\right)-v\left(B_{L}\right)\right]}_{\rho^{B}}
$$

where

$$
\frac{\partial x^{B}\left(B_{L}, S_{L}\right)}{\partial \alpha^{B}}=\frac{\delta v\left(B_{L}\right)\left[\epsilon x^{B}\left(B_{L}, S_{L}\right)-1\right]}{D^{B}}<0 \quad \text { with } x^{B}\left(B_{L}, S_{L}\right)=\frac{N^{B}}{D^{B}}
$$

The interpretation of the three terms is similar to Case $I . \rho^{S}$ and $\rho^{B}$ describe the loss from a lower $x_{L}^{L}$ induced by a higher $\alpha$. The reason for this negative impact 
is the same as above in Case $I . \sigma^{S}$ is the gain from a higher inside option in the case of no trade. This term is missing in $U^{B}$, because the "high" type $B_{H}$ trades with probability one. For buyer-integration to be implemented, the reduction in $x^{B}\left(B_{L}, S_{L}\right)$ in comparison to $x^{S}\left(B_{L}, S_{L}\right)$ by a higher $\alpha$ must be small enough, such that the "windfall" gain $\left(\sigma^{S}\right)$ is outweighted.

Proposition 5 If $v\left(B_{L}\right)=v\left(B_{H}\right)=v\left(S_{L}\right)=v\left(S_{H}\right)$ then $x^{S}=x^{B}$ and $U^{S}=U^{B}$. Seller-integration and buyer-intergration are equally good.

If $v\left(B_{H}\right)=v\left(S_{L}\right)>v\left(S_{H}\right)=v\left(B_{L}\right)$ then both seller-and buyer-integration, can be optimal.

No clear-cut prediction can be made. The result depends on a comparison between the gains from outside trade/consumption and the change of the probability of inside trade.

Overall, it can be stated that a higher inside option can increase opportunistic behavior and thereby the probability of no trade so much that utility is decreased in spite of the gain from a higher inside option. The higher the threat point for one party, the lower the gains from trade and thus the lower are the losses from long-winded quarrels. In this sense, the assignment of property rights has important effects on haggling (see (5, Coase(1937)) and (54, Williamson(1985))).

\subsection{Short-term Property}

As explained above, with short-term property, property rights depend on the type announcement in a direct revelation mechanism. The utilities change to:

$$
\begin{aligned}
U(B) & =B X(B)-T(B)+\epsilon \chi^{B}\left(B, S_{L}\right) v(B)\left(1-x\left(B, S_{L}\right)\right) \\
& +(1-\epsilon) \chi^{B}\left(B, S_{H}\right) v(B)\left(1-x\left(B, S_{H}\right)\right) \\
U(S) & =T(S)-S X(S)+\delta \chi^{S}\left(B_{H}, S\right) v(S)\left(1-x\left(B_{H}, S\right)\right) \\
& +(1-\delta) \chi^{S}\left(B_{L}, S\right) v(S)\left(1-x\left(B_{L}, S\right)\right)
\end{aligned}
$$

where $\chi^{B}(B, S), \chi^{S}(B, S) \in\{0,1\}, \chi^{B} \chi^{S}=0{ }^{22}$ and

$\chi^{B}(B, S)=\left\{\begin{array}{lll}0 & : & \text { property is not assigned to the buyer if }(\mathrm{B}, \mathrm{S}) \text { is annnounced } \\ 1 & : & \text { property is assigned to the buyer if }(\mathrm{B}, \mathrm{S}) \text { is annnounced }\end{array}\right.$

\footnotetext{
${ }^{22}$ We restrict to a zero-one decision, for simplicity. An extension to intermediate values is straightforward. In this case the property would be assigned to an agent for a shorter period.
} 
$\chi^{S}(B, S)=\left\{\begin{array}{lll}0 & : & \text { property is not assigned to the seller if }(\mathrm{B}, \mathrm{S}) \text { is annnounced } \\ 1 & : & \text { property is assigned to the seller if }(\mathrm{B}, \mathrm{S}) \text { is annnounced }\end{array}\right.$

The optimal allocation now entails determining the optimal $\chi^{B}$ and $\chi^{S}$. Therefore, for each pair of announced types $(B, S)$, a decision has to be taken. The seller now includes an assignment of property rights in his offer. For example, he can state "I allow you to use the asset. But if trade will not take place within the next two weeks, so delay is too long, we will return to non-integration.".

Assignment of property rights has the same effects for short-term property as for long-term property. So what changes for short-term property? Note that assigning property to $B_{L}$ means that the seller allows the buyer to use the asset while trading is delayed. This makes waiting for $B_{H}$ more attractive. Thus the seller has to further increase delay to convince $B_{H}$ to accept his immediate offer. Therefore assigning property only to $B_{H}$, and not to $B_{L}$, implies that in case of the buyer's decision to decline a first offer of the seller (He claims that the price exceeds his valuation of the item), the buyer loses his right to use the asset. This makes delay for him more costly. So assigning property only to $B_{H}$ (and not to $B_{L}$ ), which is only a possibility with state-contingent property, avoids at least partially the inefficient delay.

Therefore we focus on the consequences of this state-contingency. Assigning property to only $B_{H}$ or to only $S_{L}$ seems very promising.

But as all four effects, which have been identified in section 4.2, have still to be taken into account, this is not necessarily the optimal choice. In particular if $v\left(B_{L}\right)$ or $v\left(S_{H}\right)$ is big then not exercising the inside option would inflict big losses on the trading partners. Furthermore, since we focus on the case with $x_{H}^{H}=1$, assigning property to $B_{H}$ neither touches $x_{L}^{L}$ nor does it generate any benefits since trade takes place immediately $\left(X\left(B_{H}\right)=1\right)$. As trade does not take place immediately for $S_{L}$ $\left(X\left(S_{L}\right)<1\right)$, assigning ownership to $S_{L}$ generates surplus while trade is delayed. Therefore assigning property only to $S_{L}$ can be optimal, in particular if $v\left(B_{L}\right)$ and $v\left(S_{H}\right)$ are small.

Proposition 6 (option contract) Assigning property only to $S_{L}$ can be optimal. We interpret this as an option (contract) for the seller, who exercises the option if $S=S_{L}$ realizes. Otherwise, if $S=S_{H}$ realizes, non-integration prevails.

By extension to a multi-asset framework, option contracts on a fraction of a firm's 
equity can be optimal. This depends on the respective magnitudes of the three effects. Thus, the change of the inside option (e.g $\left.\Delta v\left(B_{L}\right)\right)$ induced by a different assignment of property is important. This change reflects the different specificity of the assets. A higher inside option means a more general applicability.

\subsection{Property and Investment}

In the preceding sections we analyzed investment and property rights separately. In this section we discuss their interaction. More precisely, we characterize the effects of assigning property on investment incentives. The results can be interpreted as a recommendation in favour of assigning property somehow or other only if we assume long-term property, that is to say renegotiation-proof property. If this is not the case, the following analysis only has a positive character. It describes the effects of renegotiated property on investment behavior. The investments $\delta$ and $\epsilon$ are investments in human capital rather than physical capital. This means that investment is tied to agents rather than being embodied in one of the assets. Consequently, the investment, e.g. in $\delta$, increases gains from trade only if the buyer is a party to the transaction. The human capital is asset-specific and embodied in the buyer and is therefore not transferable. One can see this by noting that the inside option of each party is independent of the investment (in human capital) of the other party. Only a higher probability of being a "good" type increases (expected) utility in the absence of trade. The assignment of property-rights is dated before the investment decision. For convenience we recapitulate the (ex-ante expected) utility of the buyer and the seller (for buyer-integration, $v\left(B_{H}\right)=\alpha v\left(B_{L}\right)=\alpha k$ ).

$$
\begin{aligned}
E(U(B)) & =\delta \epsilon x_{L}^{L}\left(B_{H}-B_{L}\right)+\delta\left(1-\epsilon x_{L}^{L}\right)\left(v\left(B_{H}\right)-v\left(B_{L}\right)\right)+v\left(B_{L}\right) \\
E(U(S)) & =\delta \epsilon\left(S_{H}-S_{L}\right)
\end{aligned}
$$

To understand the impact of buyer integration $\left(v\left(B_{L}\right)>0\right)$ on investment of the buyer (the decision of the seller is unaffected) we calculate $\frac{\partial^{2} E(U(B))}{\partial \delta \partial k}$.

$$
\begin{array}{r}
\frac{\partial^{2} E(U(B))}{\partial \delta \partial k}=\epsilon\left(B_{H}-B_{L}\right)[\underbrace{\frac{\partial x_{L}^{L}}{\partial k}}_{\mu}+\underbrace{\delta \frac{\partial^{2} x_{L}^{L}}{\partial k \partial \delta}}_{\nu}] \\
+\quad(\alpha-1)\left[1-\epsilon x_{L}^{L}+\delta \frac{\partial x_{L}^{L}}{\partial \delta}\right) \\
\left.-\epsilon\left(\frac{\partial x_{L}^{L}}{\partial k}+\frac{\partial^{2} x_{L}^{L}}{\partial \delta \partial k}\right)\right]
\end{array}
$$


We concentrate on the effects $\mu$ and $\nu$ and ignore those induced by the typedependency of the inside options (the latter addend is zero if $\alpha$ equals 1). Effect $\mu$ is negative because a higher $k$ decreases $x_{L}^{L}$ and thus decreases investment incentives, which are proportional to $x_{L}^{L}$. Non-integration, by preventing haggling, enforces higher trade, which we interpret as greater cooperation, which encourages higher investment. Effect $\nu$ is positive. A higher $k$ decreases the disincentive effects more than the incentive affects of a higher $\delta$. Thereby the bargaining hold-up effect is reduced and thus investment is stimulated. Since these two effects are counteracting, no clear-cut prediction results.

We want to complete this subsection by linking it to the discussion about (non)renegotiation of property in section 4.1. This and the last paragraph have shown that a different ownership structure can be efficient at the interim stage than at the ex-ante stage. This happens whenever integration is favoured at the bargaining stage but attenuates investment incentives at the ex-ante stage. Thus, the parties may have an incentive to commit to a fixed ownership assignment.

\subsection{Penalty doctrine}

We will now discuss the impact of individual-rationality constraints, which, in the light of our incentive interpretation, must be respected. In particular, we consider the benefits and losses of giving up this assumption. Interpreting individual-rationality constraints as a consequence of the penalty doctrine (see e.g Edlin and Hermalin (1998)), whereby a court prevents losses because of its abhorrence of forfeiture, amounts to a re-evaluation of its justification on economic grounds. Forbidding high penalties in the case of no trade amounts to assuming a lower bound on the feasible individual rationality constraints.

Without our assumptions of a nonnegative individual-rationality constraint Schmitz (2002a) shows that, incorporating the insights of Cramton,Gibbons and Klemperer (1987) and Rogerson (1992), efficient trade can be reached ${ }^{23}$. This immediately results in efficient selfish investment.

But what about cooperative investment in terms of efficiency? Schmitz (2002b) shows that joint efficiency, so to say efficient trade and efficient (cooperative) investment is not possible. The penalty doctrine now serves as a commitment device to inefficient trade if otherwise individual-rationality constraints can be circumvented contractually. The penalty doctrine has an economic justification if it stimulates

\footnotetext{
${ }^{23}$ Neeman (1999) also makes use of the basic intuition of Cramton,Gibbons and Klemperer (1987) to improve the outcome of bargaining under asymmetric information in a public good problem.
} 
cooperative investment by preventing efficient trade and thereby increases welfare. The results of high incentives for cooperative investment shown in sections 3.2 and 3.3 are promising for this purpose. To this end, we calculate the maximal incentives for cooperative investment by the seller when trade is efficient. We assume that the buyer and the seller alone cannot commit to an inefficient outcome. We restrict ourselves to independent valuations but note that an extension to dependent valuations is straightforward. Remember that

$$
\begin{aligned}
U\left(S_{L}\right) & =\delta t\left(B_{H}, S_{L}\right)+(1-\delta) t\left(B_{L}, S_{L}\right)-S_{L} \\
U\left(S_{H}\right) & =\delta t\left(B_{H}, S_{H}\right)+(1-\delta) t\left(B_{L}, S_{H}\right)-\delta S_{H} \\
E(U(S)) & =\delta T\left(B_{H}\right)+(1-\delta) T\left(B_{L}\right)-\epsilon S_{L}-\delta(1-\epsilon) S_{H}
\end{aligned}
$$

Therefore

$$
\begin{aligned}
\frac{\partial E(U(S))}{\partial \delta}= & T\left(B_{H}\right)-T\left(B_{L}\right)-(1-\epsilon) S_{H} \\
& \in\left[\left(B_{L}-S_{H}\right)(1-\epsilon),\left(B_{H}-S_{H}\right)(1-\epsilon)\right]
\end{aligned}
$$

using the incentive constraints of the buyer. Since with inefficient trade $\frac{\partial E(U(S))}{\partial \delta}=$ $\left(S_{H}-S_{L}\right) \epsilon$, in certain circumstances ${ }^{24}$ welfare can be increased by being able to commit to inefficient trade. This highlights the point that institutions such as the penalty doctrine can be a valuable commitment device.

\section{Concluding Remarks}

We started from the observation that asymmetric information at the bargaining stage may be a valuable ingredient in approaching a possible foundation of incomplete contracting. We recognized that a necessary first step to succeed with such an approach is to ensure that the results, which have been derived so far in the literature, still hold at least qualitatively. Thus we then asked first how investment incentives change and second if property rights still matter with asymmetric information.

We provided answers to both questions.

First we presented an analysis of the investment incentives with asymmetric information. We discoverd a new effect, called the bargaining hold-up effect, which comprises the change of the allocation due to investment. We then showed that

\footnotetext{
${ }^{24}$ Numerical values can easily be found by making use of the proof of proposition B.
} 
(joint) cooperative overinvestment can be a result.

Second we modeled property rights in such a way that they still matter although the agents desist from writing a contract otherwise. We characterized the optimal assigment of ownership and we showed that both the assignment of property and the degree of asset specificity affects gains from trade.

Therefore, in summary, we can conclude that contracting with private information not only makes it possible to retrieve the insights of contracting with symmetric information, but also makes it possible to derive new insights. 


\section{A Proof of Propositions}

\section{Proof of Proposition 1}

Consider $\hat{e}^{b}>e^{b}$ first and fix $e^{s}$. Let $r=r\left(e^{b}, e^{s}\right)$ where

$$
\begin{aligned}
r\left(e^{b}, e^{s}\right) \quad \text { solves } \\
\\
\Gamma(r) \equiv \int_{c_{1}}^{c_{2}} \int_{v_{1}}^{v_{2}}\left[c_{b}(v, 1)-c_{s}(c, 1)\right] \phi^{r}(v, c) f_{b}\left(v \mid e^{b}\right) f_{s}\left(c \mid e^{c}\right) d v d c=0
\end{aligned}
$$

and so the optimal policy is $\phi^{r}(\cdot, \cdot)$. Correspondingly let $\bar{c}$ be the highest $c$ for which trade takes place and $v(c)$ be the smallest $v$ for which trade takes place if the valuation of the seller equals $c$. Then define $\hat{v}(c):=F_{b}^{-1}\left(F_{b}\left(v(c) \mid e^{b}\right) \mid \hat{e}^{b}\right)>v(c)$ so that trade takes place for $(v, c)$ in the new allocation whenever $\hat{v}(c) \geq v$. We check implementability first, this means we show that $\hat{\Gamma} \geq 0$. Since the allocation $\phi^{r}(\cdot, \cdot)$ is optimal given $\left(e^{b}, e^{s}\right)$ and

$$
\begin{aligned}
\int_{v_{1}}^{v_{2}}\left[c_{b}(v, 1) \phi^{r}(v, c) f_{b}\left(v \mid e^{b}\right) d v\right. & =\int_{v(c)}^{v_{2}}\left[v f_{b}\left(v \mid e^{b}\right)+F_{b}\left(v \mid e^{b}\right)-1\right] d v \\
& =v(c)\left(1-F_{b}\left(v(c) \mid e^{b}\right)\right),
\end{aligned}
$$

it holds that

$$
\int_{c_{1}}^{\bar{c}}\left(1-F_{b}\left(v(c) \mid e^{b}\right)\right) \cdot\left(v(c)-c_{s}(c, 1)\right) f_{s}\left(c \mid e^{s}\right) d c=0
$$

Therefore

$$
\begin{aligned}
\hat{\Gamma} & =\int_{c_{1}}^{\bar{c}}\left(1-F_{b}\left(\hat{v}(c) \mid \hat{e}^{b}\right)\right) \cdot\left(\hat{v}(c)-c_{s}(c, 1)\right) f_{s}\left(c \mid e^{s}\right) d c \\
& =\int_{c_{1}}^{\bar{c}}\left(1-F_{b}\left(v(c) \mid e^{b}\right)\right) \cdot\left(v(c)-c_{s}(c, 1)+\hat{v}(c)-v(c)\right) f_{s}\left(c \mid e^{s}\right) d c \\
& =\int_{c_{1}}^{\bar{c}}\left(1-F_{b}\left(v(c) \mid e^{b}\right)\right) \cdot(\hat{v}(c)-v(c)) f_{s}\left(c \mid e^{s}\right) d c>0
\end{aligned}
$$

so that implementability can be ensured. It remains to be shown that the new 
allocation results in a higher value. The surplus equals

$$
\begin{aligned}
& \int_{c_{1}}^{\bar{c}} \int_{\hat{v}(c)}^{v_{2}}(v-c) f_{b}\left(v \mid \hat{e}^{b}\right) f_{s}\left(c \mid e^{s}\right) d v d c \\
= & \int_{c_{1}}^{\bar{c}}\left\{\int_{F_{b}\left(v(c) \mid e^{b}\right)}^{1}\left(F_{b}^{-1}\left(z \mid \hat{e}^{b}\right)-c\right) d z\right\} f_{s}\left(c \mid e^{s}\right) d c \\
> & \int_{c_{1}}^{\bar{c}}\left\{\int_{F_{b}\left(v(c) \mid e^{b}\right)}^{1}\left(F_{b}^{-1}\left(z \mid e^{b}\right)-c\right) d z\right\} f_{s}\left(c \mid e^{s}\right) d c \\
= & \int_{c_{1}}^{\bar{c}} \int_{v(c)}^{v_{2}}(v-c) f_{b}\left(v \mid e^{b}\right) f_{s}\left(c \mid e^{s}\right) d v d c,
\end{aligned}
$$

which is the surplus for $\phi^{r}$.

The proof for $e^{s}$ follows along the same line of argument by defining $\hat{c}(v):=$ $F_{s}^{-1}\left(F_{s}\left(c(v) \mid e^{s}\right) \mid \hat{e}^{s}\right)<c(v)$ for $\hat{e}^{s}>e^{s}$.

The following lemma is useful for solving linear programming problems:

Lemma 1 (Characterization Theorem of Linear Programming) Let $A$ be an $(m, n)$ matrix, $c \in \Re^{n}$ and $b \in \Re^{m}$. Consider the following linear optimization problem $(M)$ :

\section{$(M)$ : Minimize $c^{T} x$ subject to $A x \geq b$}

Then, $\bar{x} \in \Re^{n}$ with $A \bar{x} \geq b$ is a global minimum for $(M)$ iff there exists a $\bar{y} \in \Re^{m}$ satisfying:

(1) $c=A^{T} \bar{y}$ (2) $\bar{y} \geq 0$ (3) $\bar{y}^{T}(A \bar{x}-b)=0$.

The preceding lemma has the following implications:

Consider the same LP problem $(M)$ as above.

Let $\bar{y}_{i}=0$, wloG $i=m$, define $\tilde{y}, \tilde{b} \in \Re^{(m-1)}$ by $\tilde{y}_{i}=\bar{y}_{i}, \tilde{b}_{i}=b_{i}$ for $i=1 \ldots m-1$ and $\tilde{A}^{T}=\left(A_{1}^{T} \ldots A_{(m-1)}^{T}\right)$. Then, $\tilde{y}_{i} \geq 0$ for $i=1 \ldots m-1$ and $\tilde{y}(\tilde{A} \bar{x}-\tilde{b})=0$. Then by using the lemma $\bar{x}$ is a global minimum for the LP problem $(\tilde{M})$ defined by

$$
(\tilde{M}): \text { Minimize } c^{T} x \text { subject to } \tilde{A} x \geq \tilde{b}
$$

This means that all constraints whose multiplier is equal to zero in the optimum can be skipped and $\bar{x}$ remains a solution (in a linear programming problem uniqueness is generally not fulfilled). 
The following assumption ensures an inefficient outcome of the bargaining (see Matsuo (1989) and Gresik (1991a)).

\section{Assumption A}

$$
\begin{aligned}
B_{H} & >S_{H}>B_{L}>S_{L} \\
& (1-\epsilon) \delta B_{H}+\epsilon B_{L}<\delta S_{H}+(1-\delta) \epsilon S_{L}
\end{aligned}
$$

We can now characterize the optimal mechanism.

\section{Proposition A}

Assume $\frac{B_{H}-S_{H}}{\frac{\epsilon}{1-\epsilon}\left(S_{H}-S_{L}\right)+S_{H}-B_{H}} \geq \frac{B_{L}-S_{L}}{\frac{\delta}{1-\delta}\left(B_{H}-B_{L}\right)+S_{L}-B_{L}}$.

Then the optimal trade mechanism entails:

$$
\begin{aligned}
x_{L}^{H} & =x_{H}^{H}=1, \\
x_{L}^{L} & =\frac{\delta\left(B_{H}-S_{H}\right)}{\epsilon(1-\delta)\left\{\left(B_{H}-B_{L}\right) \frac{\delta}{(1-\delta)}-\left(B_{L}-S_{L}\right)\right\}}<1, \\
x_{H}^{L} & =0, \\
t_{L}^{H} & =B_{H}-\left(B_{H}-B_{L}\right) x_{L}^{L}+\frac{1-\epsilon}{\epsilon}\left(B_{H}-S_{H}\right)=S_{H}-\frac{1-\delta}{\delta}\left(B_{L}-S_{L}\right) x_{L}^{L}, \\
t_{H}^{H} & =S_{H}, t_{L}^{L}=B_{L} x_{L}^{L}, t_{H}^{L}=0 .
\end{aligned}
$$

\section{Proof of Proposition A}

Define the expected probability of trade and transfer as

$\left.X(B):=x\left(B, S_{H}\right)(1-\epsilon)+x\left(B, S_{L}\right) \epsilon\right)$,

$X(S):=x\left(B_{H}, S\right) \delta+x\left(B_{L}, S\right)(1-\delta)$,

$T(B):=t\left(B, S_{H}\right)(1-\epsilon)+t\left(B, S_{L}\right) \epsilon$,

$T(S):=t\left(B_{H}, S\right) \delta+t\left(B_{L}, S\right)(1-\delta)$,

with $B \in\left\{B_{H}, B_{L}\right\}$ and $S \in\left\{S_{H}, S_{L}\right\}$.

The agents have to solve the following problem $(\mathbf{P})$ :

$$
\begin{array}{cc}
\operatorname{Max}_{x(\cdot), t(\cdot)} \quad(1-\gamma)\left\{\delta\left(B_{H} X\left(B_{H}\right)-T\left(B_{H}\right)\right)+(1-\delta)\left(B_{L} X\left(B_{L}\right)-T\left(B_{L}\right)\right\}\right. \\
+\quad \gamma\left\{\epsilon\left(T\left(S_{L}\right)-S_{L} X\left(S_{L}\right)\right)+(1-\epsilon)\left(T\left(S_{H}\right)-S_{H} X\left(S_{H}\right)\right)\right\}
\end{array}
$$

subject to

- Incentive constraints (IC) 
IC of $B_{H}: \quad B_{H} X\left(B_{H}\right)-T\left(B_{H}\right) \geq B_{H} X\left(B_{L}\right)-T\left(B_{L}\right)$

IC of $B_{L}: \quad B_{L} X\left(B_{L}\right)-T\left(B_{L}\right) \geq B_{L} X\left(B_{H}\right)-T\left(B_{H}\right)$

IC of $S_{L}: \quad\left(S_{L}\right)-S_{L} X\left(S_{L}\right) \geq T\left(S_{H}\right)-S_{H} X\left(S_{H}\right)$

IC of $S_{H}: \quad T\left(S_{H}\right)-S_{H} X\left(S_{H}\right) \geq T\left(S_{L}\right)-S_{H} X\left(S_{L}\right)$

- Interim individual rationality constraints (IIR)

IIR of $B_{H}: \quad B_{H} X\left(B_{H}\right)-T\left(B_{H}\right) \geq 0$

IIR of $B_{L}: \quad B_{L} X\left(B_{L}\right)-T\left(B_{L}\right) \geq 0$

IIR of $S_{L}: \quad T\left(S_{L}\right)-S_{L} X\left(S_{L}\right) \geq 0$

IIR of $S_{H}: \quad T\left(S_{H}\right)-S_{H} X\left(S_{H}\right) \geq 0$

Standard arguments (standard Kuhn-Tucker approach) show that $U\left(B_{L}\right)=$ $U\left(S_{H}\right)=0, U\left(B_{H}\right)=X\left(B_{L}\right)\left(B_{H}-B_{L}\right)=\epsilon x\left(B_{L}, S_{L}\right)\left(B_{H}-B_{L}\right)$ and $U\left(S_{L}\right)=$ $X\left(S_{H}\right)\left(S_{H}-S_{L}\right)=\delta \epsilon x\left(B_{H}, S_{H}\right)\left(S_{H}-S_{L}\right)$ in the optimum and that it suffices to solve the following maximization problem to determine the optimum.

$$
\begin{aligned}
\operatorname{Max}_{x(\cdot), t(\cdot)} & (1-\gamma)\left\{\delta\left(B_{H} X\left(B_{H}\right)-T\left(B_{H}\right)\right)+(1-\delta)\left(B_{L} X\left(B_{L}\right)-T\left(B_{L}\right)\right\}\right. \\
+ & \gamma\left\{\epsilon\left(T\left(S_{L}\right)-S_{L} X\left(S_{L}\right)\right)+(1-\epsilon)\left(T\left(S_{H}\right)-S_{H} X\left(S_{H}\right)\right)\right\}
\end{aligned}
$$

subject to

$$
\begin{aligned}
\Gamma & =\text { "Expected gains from trade }(\mathrm{W})-\text { information rents" } \\
& =x\left(B_{H}, S_{L}\right) \delta \epsilon\left(B_{H}-S_{L}\right) \\
& +x\left(B_{L}, S_{L}\right)(1-\delta) \epsilon\left[\left(B_{L}-S_{L}\right)-\frac{\delta}{1-\delta}\left(B_{H}-B_{L}\right)\right] \\
& +x\left(B_{H}, S_{H}\right) \delta(1-\epsilon)\left[\left(B_{H}-S_{H}\right)-\frac{\epsilon}{1-\epsilon}\left(S_{H}-S_{L}\right)\right] \geq 0
\end{aligned}
$$

The same argument as in (53, Williams(1987)) or the Characterization Theorem of Linear Programming (see above) shows $\Gamma=0$ in the optimum.

It follows that $x\left(B_{H}, S_{H}\right)=1$ if

$$
\frac{B_{H}-S_{H}}{\frac{\epsilon}{1-\epsilon}\left(S_{H}-S_{L}\right)+S_{H}-B_{H}}>\frac{B_{L}-S_{L}}{\frac{\delta}{1-\delta}\left(B_{H}-B_{L}\right)+S_{L}-B_{L}}
$$

Since $x\left(B_{H}, S_{L}\right)=1, x\left(B_{L}, S_{L}\right)<1$ then solves $\Gamma=0$.

The transfers specified in the proposition implement the allocation and even fulfill ex-post individual-rationality constraints. 
Let $I_{t}^{A}$ indicates the private incentives of agent $A \in\{B, S\}$, where $t \in\{s, c\}$ denotes (s)elf- and (c)ooperative investment, respectively. One can think of $I_{t}^{A}$ as the (Nash)equilibrium strategy of agent $A$ at the investment stage.

Proposition B The following statements hold:

- Investment in Cost Reduction ( $\epsilon)$ :

$$
\epsilon^{*}>I_{s}^{S}=\epsilon_{\text {asym }}^{*}>I_{c}^{B}=0
$$

- Investment in Value Increase ( $\delta)$ :

- Seller: The following cases can emerge:

$$
\begin{aligned}
I_{c}^{S} & >\max \left(\delta^{*}, \delta_{\text {asym }}^{*}\right) \\
I_{c}^{S} & <\min \left(\delta^{*}, \delta_{\text {asym }}^{*}\right) \\
\delta_{\text {asym }}^{*}>I_{c}^{S} & >\delta^{*} \\
\delta^{*}>I_{c}^{S} & >\delta_{\text {asym }}^{*}
\end{aligned}
$$

- Buyer: The following cases can emerge:

$$
\begin{aligned}
0 & =I_{s}^{B}<\min \left(\delta^{*}, \delta_{\text {asym }}^{*}\right) \\
0 & <I_{s}^{B}<\min \left(\delta^{*}, \delta_{\text {asym }}^{*}\right) \\
\delta_{\text {asym }}^{*} & >I_{s}^{B}>\delta^{*}
\end{aligned}
$$

All these comparisons arise from partial marginal analysis, but this carries over to an equilibrium analysis by choosing appropriate cost functions.

\section{Proof of Proposition B}

We first compare the partial effects of investment by using examples to show that all claimed constellations can emerge. We then comment on equilibrium effects.

We begin with some general statements to clarify the table preceding the proposition. The utility of the buyer is independent of $\epsilon$, and thus the buyer has no incentive for cooperative investment. The effect of $\delta$ on $E(U(B))$ is ambiguous (see the examples below) because, on the one hand, a higher $\delta$ decreases $x\left(B_{L}, S_{L}\right)^{25}$ and, on the other hand, it increases the probability of $B_{H}$ and thus the probability $25 \frac{\partial x\left(B_{L}, S_{L}\right)}{\partial \delta}=\frac{-\epsilon\left(B_{H}-S_{H}\right)\left(B_{L}-S_{L}\right)}{\left[\left(B_{H}-B_{L}\right) \delta \epsilon-\left(B_{L}-S_{L}\right) \epsilon(1-\delta)\right]^{2}}<0$ 
of receiving an information rent. Both types of investments have an unambiguous positive effect on the utility of the seller.

The first remark implies $I_{s}^{S}=\epsilon_{\text {asym }}^{*}>I_{c}^{B}=0$. The missing inequality stating that incentives are greater with symmetric information, follows from comparing the marginal revenue with symmetric information $\left[\delta\left(S_{H}-S_{L}\right)+(1-\delta)\left(B_{L}-S_{L}\right)\right]$ to the marginal revenue with asymmetric information $\left[\delta\left(S_{H}-S_{L}\right)\right]$.

The consideration of the $\delta$ investment is a little bit more cumbersome because of its above-mentioned ambiguous effects on $E(U(B))$ and the possibility of greater incentives with asymmetric information than with symmetric information. Distinguishing the following three effects simplifies the analysis.

Marginal revenue with symmetric information :

$$
\epsilon\left(B_{H}-S_{L}\right)+(1-\epsilon)\left(B_{H}-S_{H}\right)-\epsilon\left(B_{L}-S_{L}\right)=B_{H}-(1-\epsilon) S_{H}-\epsilon B_{L}
$$

Marginal revenue of the buyer :

$$
\epsilon\left(B_{H}-B_{L}\right) \frac{\partial \delta x\left(B_{L}, S_{L}\right)}{\partial \delta}=\epsilon^{2}\left(B_{H}-B_{L}\right) \delta\left(B_{H}-S_{H}\right) \frac{\delta B_{H}+S_{L}(2-\delta)-2 B_{L}}{\left[B_{H} \delta \epsilon+S_{L}(1-\delta) \epsilon-B_{L} \epsilon\right]^{2}}
$$

Marginal revenue of the seller :

$$
\epsilon\left(S_{H}-S_{L}\right)
$$

The sum of the last two effects is the marginal revenue with asymmetric information. Thus $I_{c}^{S}<(>) \delta_{\text {asym }}^{*}$ if, and only if $\frac{\partial \delta x\left(B_{L}, S_{L}\right)}{\partial \delta}>(<) 0$, this means if an increase of $\delta$ has an positve(negative) effect on the (expected) utility of the buyer. Moreover, $I_{s}^{B}>0 \Leftrightarrow \frac{\partial \delta x\left(B_{L}, S_{L}\right)}{\partial \delta}>(<) 0$. Therefore, the three cases for the buyer can easily be treated after we have dealt with the cases for the seller.

The following table presents numerical values showing that all asserted cases are possible.

\begin{tabular}{c|c||c|c|c|c|c|c} 
& & $B_{H}$ & $S_{H}$ & $B_{L}$ & $S_{L}$ & $\epsilon$ & $\delta$ \\
\hline \hline $\mathrm{a})$ & $I_{c}^{S}>\max \left(\delta^{*}, \delta_{\text {asym }}^{*}\right)$ & 2 & $\frac{7}{4}$ & 1 & 0 & $\frac{1}{2}$ & $\frac{9}{10}$ \\
\hline $\mathrm{b})$ & $I_{c}^{S}<\min \left(\delta^{*}, \delta_{\text {asym }}^{*}\right)$ & 3 & $\frac{9}{4}$ & 1 & 0 & $\frac{1}{2}$ & $\frac{3}{4}$ \\
\hline $\mathrm{c})$ & $\delta_{\text {asym }}^{*}>I_{c}^{S}>\delta^{*}$ & 3 & $\frac{11}{4}$ & 1 & 0 & $\frac{1}{2}$ & $\frac{3}{4}$ \\
\hline $\mathrm{d})$ & $\delta^{*}>I_{c}^{S}>\delta_{\text {asym }}^{*}$ & 2 & $\frac{3}{2}$ & 1 & 0 & $\frac{5}{8}$ & $\frac{9}{10}$ \\
\hline
\end{tabular}

We have to bear in mind that in addition to comparing marginal revenues, one must also check assumption A, guaranteeing an inefficient outcome, and ensure that the parameters are consistent with $x_{H}^{H}=1$.

Observe now that 


$$
\begin{aligned}
& \left.\left.I_{s}^{B}<\min \left(\delta^{*}, \delta_{\text {asym }}^{*}\right) \text { in cases a }\right) \text { and } \mathrm{d}\right) \\
& \left.0<I_{s}^{B}<\min \left(\delta^{*}, \delta_{\text {asym }}^{*}\right) \text { in case } \mathrm{c}\right) \\
& \delta_{\text {asym }}^{*}>I_{s}^{B}>\delta^{*} \text { in case b) }
\end{aligned}
$$

Thus, the consideration of the partial effects is completed. In (Nash-)equilibrium and in the social optimum problems we have to take into account that investment decisions are strategic substitutes. As usual, this can strengthen over- and underinvestment. Therefore, the results depend on cost functions, which can be easily found for each of the cases discussed above.

\section{Assumption B}

$$
\begin{array}{r}
B_{H}>S_{H}>B_{L}>S_{L} \\
\left(B_{H}-S_{H}\right) \alpha_{1}+\left(B_{L}-S_{L}\right) \alpha_{2}-\left(S_{H}-B_{L}\right)>0
\end{array}
$$

Proposition C [Gresik (1991b)] Set $t\left(B_{L}, S_{H}\right)=0$. Then a trading-mechanism is ex-post efficient, incentive compatible and fulfills interim individual-rationality constraints if, and only if Assumption $B$ is fulfilled ${ }^{26}$.

\section{Proof of Proposition C}

Before stating the short proof, which follows Gresik(1991b), we need some definitions.

Define the expected probability of trade $X(\tilde{\theta}, \theta)$ and transfer $T(\tilde{\Theta}, \Theta)$ for reported type $\tilde{\theta}$ and true type $\theta$ as

$$
\begin{aligned}
X(\tilde{B}, B) & =x\left(\tilde{B}, S_{H}\right) p\left(S_{H} \mid B\right)+x\left(\tilde{B}, S_{L}\right) p\left(S_{L} \mid B\right) \\
X(\tilde{S}, S) & =x\left(B_{H}, \tilde{S}\right) p\left(B_{H} \mid S\right)+x\left(B_{L}, \tilde{S}\right) p\left(B_{L} \mid S\right) \\
T(\tilde{B}, B) & =t\left(\tilde{B}, S_{H}\right) p\left(S_{H} \mid B\right)+t\left(\tilde{B}, S_{L}\right) p\left(S_{L} \mid B\right) \\
T(\tilde{S}, S) & =t\left(B_{H}, \tilde{S}\right) p\left(B_{H} \mid S\right)+t\left(B_{L}, \tilde{S}\right) p\left(B_{L} \mid S\right)
\end{aligned}
$$

\footnotetext{
${ }^{26}$ Sufficiency is not needed in the subsequent analysis.
} 
where $p(S \mid B)=\frac{p(B, S)}{p(B)}$ and $p(B \mid S)=\frac{p(B, S)}{p(S)}$ are the conditional probability given $B$ respectively $S$, with $B \in\left\{B_{H}, B_{L}\right\}$ and $S \in\left\{S_{H}, S_{L}\right\}$.

A interim-incentive compatible mechanism fulfilling interim individualrationality constraints satisfies the following equations :

- Interim Incentive constraints (BIC)

IC of $B_{H}$ :

$$
B_{H} X\left(B_{H}, B_{H}\right)-T\left(B_{H}, B_{H}\right) \geq B_{H} X\left(B_{L}, B_{H}\right)-T\left(B_{L}, B_{H}\right)
$$

$\mathrm{IC}$ of $B_{L}$ :

$$
B_{L} X\left(B_{L}, B_{L}\right)-T\left(B_{L}, B_{L}\right) \geq B_{L} X\left(B_{H}, B_{L}\right)-T\left(B_{H}, B_{L}\right)
$$

IC of $S_{H}$ :

$$
T\left(S_{H}, S_{H}\right)-S_{H} X\left(S_{H}, S_{H}\right) \geq T\left(S_{L}, S_{H}\right)-S_{H} X\left(S_{L}, S_{H}\right)
$$

IC of $S_{L}$ :

$$
T\left(S_{L}, S_{L}\right)-S_{L} X\left(S_{L}, S_{L}\right) \geq T\left(S_{H}, S_{L}\right)-S_{L} X\left(S_{H}, S_{L}\right)
$$

- Interim individual-rationality constraints (IIR)

IIR of $B_{H}$ :

$$
B_{H} X\left(B_{H}, B_{H}\right)-T\left(B_{H}, B_{H}\right) \geq 0
$$

IIR of $B_{L}$ :

$$
B_{L} X\left(B_{L}, B_{L}\right)-T\left(B_{L}, B_{L}\right) \geq 0
$$

IIR of $S_{L}:$

$$
T\left(S_{L}, S_{L}\right)-S_{L} X\left(S_{L}, S_{L}\right) \geq 0
$$

IIR of $S_{H}$ :

$$
T\left(S_{H}, S_{H}\right)-S_{H} X\left(S_{H}, S_{H}\right) \geq 0
$$


To prove the necessity of equation 5 we first multiply 6 by $\left(1+\alpha_{1}\right)$ and 9 by $\left(1+\alpha_{2}\right)$. Adding these two products results in $\alpha_{1} B_{H}-\alpha_{2} S_{L}-t\left(B_{H}, S_{H}\right)\left(1+\alpha_{1}\right)+$ $t\left(B_{L}, S_{L}\right)\left(1+\alpha_{2}\right) \geq 0$. To get an expression independent of the transfers (here the restriction $t\left(B_{L}, S_{H}\right)=0$ is essential) we add $\frac{\left(1+\alpha_{2}\right)}{p\left(S_{L} \mid B_{L}\right)}$ times 11 and $\frac{\left(1+\alpha_{1}\right)}{p\left(B_{H} \mid S_{H}\right)}$ times 13. This is equation 5. We can also show sufficiency. Therefore, set $t\left(B_{L}, S_{H}\right)=0$, $t\left(B_{L}, S_{L}\right)=B_{L}, t\left(B_{H}, S_{H}\right)=S_{H}$ and choose $t\left(B_{H}, S_{L}\right)$ such that

$$
\max \left\{B_{L}, S_{H}-\alpha_{2}\left(B_{L}-S_{L}\right)\right\} \leq t\left(B_{H}, S_{L}\right) \leq \min \left\{S_{H}, B_{L}+\alpha_{1}\left(B_{H}-S_{H}\right)\right\}
$$

If equation 5 holds, then such a value exists and all 6 to 13 constraints are fulfilled.

As in section 3.2 we can focus on the case where $x_{H}^{H}=1\left(\right.$ and $\left.x_{L}^{L}<1\right)$.

\section{Proposition D}

Assume $\frac{\alpha_{1}\left(B_{H}-S_{H}\right)}{\left(S_{H}-S_{L}\right)-\alpha_{1}\left(B_{H}-S_{H}\right)} \geq \frac{\alpha_{2}\left(B_{L}-S_{L}\right)}{\left(B_{H}-B_{L}\right)-\alpha_{2}\left(B_{L}-S_{L}\right)}, x\left(B_{L}, S_{H}\right)=t\left(B_{L}, S_{H}\right)=0$.

Then the optimal trade mechanism entails:

$$
\begin{aligned}
x_{L}^{H} & =x_{H}^{H}=1, \\
x_{L}^{L} & =\frac{\left(1+\alpha_{1}\right) q\left(B_{H}-S_{H}\right)}{q\left[\left(B_{H}-B_{L}\right)-\alpha_{2}\left(B_{L}-S_{L}\right)\right]}<1, \\
x_{H}^{L} & =0, \\
t_{L}^{H} & =B_{L}+\left(B_{H}-B_{L}\right)\left(1-x_{L}^{L}\right)+\left(B_{H}-S_{H}\right) \alpha_{1}=S_{H}+\left(S_{L}-B_{L}\right) \alpha_{2} x_{L}^{L}, \\
t_{H}^{H} & =S_{H}, t_{L}^{L}=B_{L} x_{L}^{L}, t_{H}^{L}=0 .
\end{aligned}
$$

\section{Proof of Proposition D}

We have to solve the following optimization problem (for notation see the proof of Proposition C) :

$$
\begin{aligned}
\operatorname{Max}_{x(\cdot), t(\cdot)} \quad M:= & \left\{\left(1+\alpha_{1}\right) q\left(B_{H} X\left(B_{H}, B_{H}\right)-T\left(B_{H}, B_{H}\right)\right)\right. \\
+ & \left(1-\left(1+\alpha_{1}\right) q\right)\left(B_{L} X\left(B_{L}, B_{L}\right)-T\left(B_{L}, B_{L}\right)\right\} \\
+ & \left\{\left(1+\alpha_{2}\right) q\right)\left(T\left(S_{L}, S_{L}\right)-S_{L} X\left(S_{L}, S_{L}\right)\right) \\
& \left.+\quad\left(1-\left(1+\alpha_{2}\right) q\right)\left(T\left(S_{H}, S_{H}\right)-S_{H} X\left(S_{H}, S_{H}\right)\right)\right\} \\
& =q x\left(B_{H}, S_{L}\right)\left(B_{H}-S_{L}\right) \\
& +\quad \alpha_{1} q x\left(B_{H}, S_{H}\right)\left(B_{H}-S_{H}\right) \\
& +\quad \alpha_{2} q x\left(B_{L}, S_{L}\right)\left(B_{L}-S_{L}\right) \\
& +\quad\left(1-\left(1+\alpha_{1}+\alpha_{2}\right) q\right) x\left(B_{L}, S_{H}\right)\left(B_{L}-S_{H}\right)
\end{aligned}
$$


subject to

the constraints 6 to 13 stated in the proof of Proposition $\mathrm{C}$

$$
\begin{gathered}
\text { and } \\
x\left(B_{L}, S_{H}\right)=t\left(B_{L}, S_{H}\right)=0 .
\end{gathered}
$$

We first want to prove that the incentive compatibility constraints of $B_{H}$ and $S_{L}$ (6 and 9) and the individual-rationality constraints of $B_{L}$ and $S_{H}$ (11 and 13) are binding in the optimum. Therefore we consider the relaxed problem :

$$
\operatorname{Max}_{x(\cdot), t(\cdot)} M
$$

subject to

constraints $6,9,11$ and 13 .

It is important to state that the efficient solution is still not feasible in the relaxed problem. This can be seen by inspecting the proof of Proposition $\mathrm{C}$, where only these four constraints were used to derive the (in)efficiency criterion. Next we can show that by relaxing the problem further, through omitting yet another constraint, the efficient solution becomes implementable. This in turn implies that all four constraints in the relaxed problem are binding (see the Characterization Theorem of Linear Programming stated before the proof of Proposition A).

We demonstrate the possibility of an efficient outcome when leaving out a further constraint by presenting an explicit solution for each case (Bear in mind that we have imposed the restriction $\left.t\left(B_{L}, S_{H}\right)=0\right)$.

Without the incentive constraint of $B_{H}(6)$ :

$$
t\left(B_{H}, S_{L}\right)=B_{H}, t\left(B_{H}, S_{H}\right)=S_{H}, t\left(B_{L}, S_{L}\right)=B_{L}
$$

Without the incentive constraint of $S_{L}(9)$ :

$$
t\left(B_{H}, S_{L}\right)=S_{L}, t\left(B_{H}, S_{H}\right)=S_{H}, t\left(B_{L}, S_{L}\right)=B_{L}
$$

Without the individual-rationality constraint of $B_{L}$ (11) :

$$
t\left(B_{H}, S_{L}\right)=B_{L}, t\left(B_{H}, S_{H}\right)=S_{H}, t\left(B_{L}, S_{L}\right)=B_{L}
$$


Without the individual-rationality constraint of $S_{H}(13)$ :

$$
t\left(B_{H}, S_{L}\right)=B_{L}, t\left(B_{H}, S_{H}\right)=B_{L}, t\left(B_{L}, S_{L}\right)=B_{L}
$$

Fulfillment of all constraints can easily be checked in each case.

It follows that

$$
\begin{aligned}
U\left(B_{H}\right) & =B_{H} X\left(B_{H}, B_{H}\right)-T\left(B_{H}, B_{H}\right) \\
& =B_{H} X\left(B_{L}, B_{H}\right)-T\left(B_{L}, B_{H}\right) \\
& =\left(B_{H}-B_{L}\right) X\left(B_{L}, B_{H}\right)+B_{L}\left(X\left(B_{L}, B_{H}\right)-X\left(B_{L}, B_{L}\right)\right)+B_{L} X\left(B_{L}, B_{L}\right) \\
& +\left(T\left(B_{L}, B_{L}\right)-T\left(B_{L}, B_{H}\right)\right)-T\left(B_{L}, B_{L}\right) \\
& =\left(B_{H}-B_{L}\right) X\left(B_{L}, B_{H}\right)+B_{L}\left(X\left(B_{L}, B_{H}\right)-X\left(B_{L}, B_{L}\right)\right) \\
& +\left(T\left(B_{L}, B_{L}\right)-T\left(B_{L}, B_{H}\right)\right)
\end{aligned}
$$

and

$$
\begin{aligned}
U\left(S_{L}\right) & =T\left(S_{L}, S_{L}\right)-S_{L} X\left(S_{L}, S_{L}\right) \\
& =T\left(S_{H}, S_{L}\right)-S_{L} X\left(S_{H}, S_{L}\right) \\
& =\left(S_{H}-S_{L}\right) X\left(S_{H}, S_{L}\right)-S_{H}\left(X\left(S_{H}, S_{L}\right)-X\left(S_{H}, S_{H}\right)\right)-S_{H} X\left(S_{H}, S_{H}\right) \\
& +\left(T\left(S_{H}, S_{L}\right)-T\left(S_{H}, S_{H}\right)\right)+T\left(S_{H}, S_{H}\right) \\
& =\left(S_{H}-S_{L}\right) X\left(S_{H}, S_{L}\right)-S_{H}\left(X\left(S_{H}, S_{L}\right)-X\left(S_{H}, S_{H}\right)\right) \\
& +\left(T\left(S_{H}, S_{L}\right)-T\left(S_{H}, S_{H}\right)\right)
\end{aligned}
$$

as well as

$$
\begin{aligned}
& U\left(B_{L}\right)=B_{L} X\left(B_{L}, B_{L}\right)-T\left(B_{L}, B_{L}\right)=0 \\
& U\left(S_{H}\right)=T\left(S_{H}, S_{H}\right)-S_{H} X\left(S_{H}, S_{H}\right)=0
\end{aligned}
$$

At this point the restrictions $\left(x\left(B_{L}, S_{H}\right)=t\left(B_{L}, S_{H}\right)=0\right)$ become essential ${ }^{27}$. Thus the expressions for $U\left(B_{H}\right)$ and $U\left(S_{L}\right)$ simplify to :

$$
\begin{aligned}
U\left(B_{H}\right) & =p\left(S_{L} \mid B_{H}\right)\left(B_{H}-B_{L}\right) x\left(B_{L}, S_{L}\right) \\
U\left(S_{L}\right) & =p\left(B_{H} \mid S_{L}\right)\left(S_{H}-S_{L}\right) x\left(B_{H}, S_{H}\right)
\end{aligned}
$$

${ }^{27} t\left(B_{L}, S_{H}\right)=0$ was already needed to show that all constraints are binding in the relaxed problem. As was shown in an earlier version, available from the author upon request, $x\left(B_{L}, S_{H}\right)>0$ can be optimal if this results in a sufficient reduction of the information rents. 
We now can apply the standard procedure (cp. proof of Proposition A or (53, Williams(1987)) ). Therefore, we restrict the problem once more :

$$
\begin{aligned}
\operatorname{Max}_{x(\cdot), t(\cdot)} M & =q x\left(B_{H}, S_{L}\right)\left(B_{H}-S_{L}\right) \\
& +\alpha_{1} q x\left(B_{H}, S_{H}\right)\left(S_{H}-S_{L}\right) \\
& +\alpha_{2} q x\left(B_{L}, S_{L}\right)\left(B_{L}-S_{L}\right)
\end{aligned}
$$

subject to

$$
\Gamma=0
$$

with $\Gamma$ defined as

$$
\begin{aligned}
\Gamma & :=M-P\left(B_{H}\right) U\left(B_{H}\right)-P\left(S_{L}\right) U\left(S_{L}\right) \\
& =q x\left(B_{H}, S_{L}\right)\left(B_{H}-S_{L}\right) \\
& +\alpha_{1} q x\left(B_{H}, S_{H}\right)\left\{\left(B_{H}-S_{H}\right)-\frac{q}{\alpha_{1} q}\left(S_{H}-S_{L}\right)\right\} \\
& +\alpha_{2} q x\left(B_{L}, S_{L}\right)\left\{\left(B_{L}-S_{L}\right)-\frac{q}{\alpha_{2} q}\left(B_{H}-B_{L}\right)\right\}
\end{aligned}
$$

By comparing the factors near to $x\left(B_{H}, S_{H}\right)$ and $x\left(B_{L}, S_{L}\right)$ in $M$ and $\Gamma$ the result is immediate if all omitted constraints are fulfilled. More formally, the maximization problem can be solved by the Kuhn-Tucker method. The resulting Langrangean multiplier is equal to $\frac{\alpha_{1}\left(B_{H}-S_{H}\right)}{\left(S_{H}-S_{L}\right)-\alpha_{1}\left(B_{H}-S_{H}\right)}$ or $\frac{\alpha_{2}\left(B_{L}-S_{L}\right)}{\left(B_{H}-B_{L}\right)-\alpha_{2}\left(B_{L}-S_{L}\right)}$, whichever is the smaller. We now show the existence of a transfer function $t(\cdot)$, which solves the incentive constraints of $B_{H}$ and $S_{L}$ with equality and in addition those of $B_{L}$ and $S_{H}$ (cp. the proof of Proposition A). The other transfers are already pinned down by the allocation $x(\cdot)$ as $t\left(B_{L}, S_{L}\right)=B_{L} x\left(B_{L}, S_{L}\right), t\left(B_{H}, S_{H}\right)=S_{H} x\left(B_{H}, S_{H}\right)$ and $t\left(B_{L}, S_{H}\right)=0$. Define :

$$
\begin{aligned}
\tilde{t}\left(B_{H}, S_{L}\right) & =\left(S_{H}-S_{L}\right) x\left(B_{H}, S_{H}\right)+S_{L}-\alpha_{2}\left(B_{L}-S_{L}\right) x\left(B_{L}, S_{L}\right) \\
\hat{t}\left(B_{H}, S_{L}\right) & =-\left(B_{H}-B_{L}\right) x\left(B_{L}, S_{L}\right)+B_{H}+\alpha_{1}\left(B_{H}-S_{H}\right) x\left(B_{H}, S_{H}\right)
\end{aligned}
$$

$\tilde{t}$ and $\hat{t}$ solve the incentive compatibility constraints of $S_{L}$ and $B_{H}$ with equality. Equality of these transfers is guaranteed by $\Gamma=0$. Therefore we can fix $t:=t\left(B_{H}, S_{L}\right)=\tilde{t}\left(B_{H}, S_{L}\right)=\hat{t}\left(B_{H}, S_{L}\right)$.

Showing $S_{H}>t\left(B_{H}, S_{L}\right)>B_{L}$ is sufficient for all remaining constraints to be 
fulfilled.

$$
\begin{aligned}
t\left(B_{H}, S_{L}\right)=\hat{t}\left(B_{H}, S_{L}\right) & =-\left(B_{H}-B_{L}\right) x\left(B_{L}, S_{L}\right)+B_{H}+\alpha_{1}\left(B_{H}-S_{H}\right) \\
& =B_{L}+\left(B_{H}-B_{L}\right)\left(1-x\left(B_{L}, S_{L}\right)\right)+\alpha_{1}\left(B_{H}-S_{H}\right) \\
& >B_{L} \\
t\left(B_{H}, S_{L}\right)=\tilde{t}\left(B_{H}, S_{L}\right) & =\left(S_{H}-S_{L}\right)+S_{L}-\alpha_{2}\left(B_{L}-S_{L}\right) x\left(B_{L}, S_{L}\right) \\
& =S_{H}-\alpha_{2}\left(B_{L}-S_{L}\right) x\left(B_{L}, S_{L}\right) \\
& <S_{H}
\end{aligned}
$$

$I_{t}^{A}$ still indicates the private incentives of agent $A \in\{B, S\}$, where $t \in\{s, c\}$ denotes (s)elf- (c)ooperative investment, respectively.

Proposition $\mathbf{E}$ a) Investment in $\delta$ and $\epsilon$ has the following effects on expected utilities

$$
\begin{aligned}
& \frac{\partial E(U(S))}{\partial \epsilon}<0 \\
& \frac{\partial E(U(B))}{\partial \epsilon}>0 \\
& \frac{\partial E(U(S))}{\partial \delta}>0 \\
& \frac{\partial E(U(B))}{\partial \delta}<0 \text { if, and only if } q\left\{B_{H}-B_{L}-\left(1+2 \alpha_{2}\right)\left(B_{L}-S_{L}\right)\right\}+\delta\left(B_{H}-S_{L}\right)<0
\end{aligned}
$$

b) Simultaneous cooperative overinvestment with respect to both benchmarks is possible:

- $I_{c}^{B}>\epsilon_{\text {asym }}^{*}$ and $I_{c}^{S}>\delta_{\text {asym }}^{*}$

- $I_{c}^{B}>\epsilon^{*}$ and $I_{c}^{S}>\delta^{*}$

\section{Proof of Proposition E}

To prove $a$ ), we merely calculate four derivatives. We first deal with $\delta$. For convenience, we recapitulate the expressions for $E(U(B))$ and $E(U(S))$.

$$
\begin{aligned}
E(U(B)) & =(q+\delta)\left(B_{H}-B_{L}\right) \frac{(q+\delta)\left(1+\alpha_{1}\right)\left(B_{H}-S_{H}\right)}{(q+\delta)\left(B_{H}-B_{L}\right)-(q+\delta)\left(\frac{q \alpha_{2}-\delta}{q+\delta}\right)\left(B_{L}-S_{L}\right)} \\
& =\left(B_{H}-B_{L}\right) \frac{(q+\delta)\left(1+\alpha_{1}\right)\left(B_{H}-S_{H}\right)}{\left(B_{H}-B_{L}\right)-\left(\frac{q \alpha_{2}-\delta}{q+\delta}\right)\left(B_{L}-S_{L}\right)} \\
E(U(S)) & =(q+\delta)\left(S_{H}-S_{L}\right)
\end{aligned}
$$


The derivatives take the following form:

$$
\begin{aligned}
\frac{\partial E(U(B))}{\partial \delta}= & \left(B_{H}-B_{L}\right)\left(1+\alpha_{1}\right)\left(B_{H}-S_{H}\right) \frac{1}{q+\delta} \\
& \frac{q\left[\left(B_{H}-B_{L}\right)-\left(B_{L}-S_{L}\right)\left(1+2 \alpha_{2}\right)\right]+\delta\left(B_{H}-S_{L}\right)}{\left[\left(B_{H}-B_{L}\right)-\left(\frac{q \alpha_{2}-\delta}{q+\delta}\right)\left(B_{L}-S_{L}\right)\right]^{2}} \\
\frac{\partial E(U(S))}{\partial \delta}= & \left(S_{H}-S_{L}\right)
\end{aligned}
$$

To consider investment in $\epsilon, E(U(B))$ and $E(U(S))$ can be expressed as follows:

$$
\begin{aligned}
E(U(B)) & =(q-\epsilon)\left(B_{H}-B_{L}\right) \frac{(q-\epsilon)\left(1+\frac{q \alpha_{1}+\epsilon}{q-\epsilon}\right)\left(B_{H}-S_{H}\right)}{(q-\epsilon)\left(B_{H}-B_{L}\right)-(q-\epsilon)\left(\frac{q \alpha_{2}+2 \epsilon}{q-\epsilon}\right)\left(B_{L}-S_{L}\right)} \\
& =\left(B_{H}-B_{L}\right) \frac{q\left(1+\alpha_{1}\right)\left(B_{H}-S_{H}\right)}{\left(B_{H}-B_{L}\right)-\left(\frac{q \alpha_{2}+2 \epsilon}{q-\epsilon}\right)\left(B_{L}-S_{L}\right)} \\
E(U(S)) & =(q-\epsilon)\left(S_{H}-S_{L}\right)
\end{aligned}
$$

The derivates take the following form:

$$
\begin{aligned}
\frac{\partial E(U(B))}{\partial \epsilon}= & \left(B_{H}-B_{L}\right) q\left(1+\alpha_{1}\right)\left(B_{H}-S_{H}\right) \\
& \frac{\left(B_{L}-S_{L}\right) \frac{q\left(2+\alpha_{2}\right)}{(q-\epsilon)^{2}}}{\left[\left(B_{H}-B_{L}\right)-\left(\frac{q \alpha_{2}+2 \epsilon}{q-\epsilon}\right)\left(B_{L}-S_{L}\right)\right]^{2}} \\
\frac{\partial E(U(S))}{\partial \epsilon}= & -\left(S_{H}-S_{L}\right)
\end{aligned}
$$

Thus, part $a$ is proved.

To prove $b$ ) we first deal with partial effects(investment of the trading partner is fixed). To compare the private incentives to the first best investments with asymmetric information we only have to check for externalities. This means the former is greater than the latter if, and only if the investment has a negative externality on its trading partner, which is only taken into account in the optimum. Except for $\frac{\partial E(U(B))}{\partial \delta}$, all derivatives are unambiguous. We are left to prove the existence of parameters fulfilling the following three conditions:

1. $\left(B_{H}-S_{H}\right) \alpha_{1}+\left(B_{L}-S_{L}\right) \alpha_{2}-\left(S_{H}-B_{L}\right)<0 \quad$ (guarantees inefficiency)

2. $\frac{\alpha_{1}\left(B_{H}-S_{H}\right)}{\left(S_{H}-S_{L}\right)-\alpha_{1}\left(B_{H}-S_{H}\right)}>\frac{\alpha_{2}\left(B_{L}-S_{L}\right)}{\left(B_{H}-B_{L}\right)-\alpha_{2}\left(B_{L}-S_{L}\right)} \quad\left(x_{H}^{H}=1\right)$

3. $\left(B_{H}-B_{L}\right)<\left(1+2 \alpha_{2}\right)\left(B_{L}-S_{L}\right) \quad\left(\Leftrightarrow \frac{\partial E(U(B))}{\partial \delta} \mid \delta=0<0\right)$

As can easily be checked, by choosing the parameters as $\alpha_{1}=1, \alpha_{2}=\frac{1}{4}, B_{H}=$ 
$3, S_{H}=\frac{5}{2}, B_{L}=\frac{5}{4}, S_{L}=0$ and $q \in\left(0, \frac{4}{9}\right)$, all three conditions are fulfilled. Moreover, the comparison with the (first best) incentives with symmetric information is also in favour of the private incentives.

To handle equilibrium effects, (strategic) interactions of investment decisions must be considered. Therefore we turn to the concatenation of $\hat{\epsilon}$ and $\hat{\delta}$. This results in

$$
\hat{\delta} \circ \hat{\epsilon}=\left\{\begin{aligned}
q & \rightarrow q+\delta-\epsilon \\
\alpha_{2} & \rightarrow \frac{q \alpha_{2}-\delta+2 \epsilon}{q+\delta-\epsilon} \\
\alpha_{1} & \rightarrow \frac{\alpha_{1}(q+\delta)+\epsilon}{q+\delta-\epsilon}
\end{aligned}\right.
$$

Notice that $\hat{\delta} \circ \hat{\epsilon}=\hat{\epsilon} \circ \hat{\delta}$. Simple calculations show that private investment, $\epsilon_{\text {asym }}^{*}$ and $\delta_{\text {asym }}^{*}$ as well as $\epsilon^{*}$ and $\delta^{*}$ are (weak) substitutes, meaning that $\frac{\partial^{2} E(U(B))}{\partial \delta \partial \epsilon}<0$, $\frac{\partial^{2} E(U(S))}{\partial \delta \partial \epsilon}=0, \frac{\partial^{2} W_{a s y m}}{\partial \delta \partial \epsilon}<0$ and $\frac{\partial^{2} W}{\partial \delta \partial \epsilon}=0$.

As it is well known, this can counteract the above results. But the existence of cost functions preserving the partial effects is obvious.

Proposition F Assume:

- $\frac{\left(B_{L}-S_{L}\right)-v\left(B_{L}\right)-v\left(S_{L}\right)}{\left(B_{L}-S_{L}\right)-v\left(B_{L}\right)-v\left(S_{L}\right)-\frac{\delta}{1-\delta}\left(\left(B_{H}-B_{L}\right)-\left(v\left(B_{H}\right)-v\left(B_{L}\right)\right)\right)}<$

$$
\frac{\left(B_{H}-S_{H}\right)-v\left(B_{H}\right)-v\left(S_{H}\right)}{\left(B_{H}-S_{H}\right)-v\left(B_{H}\right)-v\left(S_{H}\right)-\frac{\epsilon}{1-\epsilon}\left(\left(S_{H}-S_{L}\right)-\left(v\left(S_{L}\right)-v\left(S_{H}\right)\right)\right)} \quad\left(x_{H}^{H}=1\right)
$$

- $v\left(B_{H}\right)-v\left(B_{L}\right)<\left(B_{H}-B_{L}\right)$

- $v\left(S_{L}\right)-v\left(S_{H}\right)<\left(S_{H}-S_{L}\right)$

Then the optimal trading mechanism entails:

$x_{L}^{H}=x_{H}^{H}=1$,

$x_{L}^{L}=\frac{\delta\left(B_{H}-S_{H}\right)-\delta v\left(B_{H}\right)-\delta v\left(S_{H}\right)}{-(1-\delta) \epsilon\left(B_{L}-S_{L}\right)+\epsilon \delta\left(B_{H}-B_{L}\right)+\epsilon v\left(B_{L}\right)+(1-\delta) \epsilon v\left(S_{L}\right)-\delta \epsilon v\left(B_{H}\right)} \quad$ and

$x_{H}^{L}=0$.

\section{Proof of Proposition F}

This proof follows the same steps as the proof of proposition A. First the individualrationality constraints of the "good" types are omitted. With type-dependent outside options this is a priori not justifiable and must be checked afterwards. This is provided for by the latter two assumptions stated in the proposition. Because the same 
constraints are binding the following $\Gamma(=\mathrm{W}$-information rents $)$ results:

$$
\begin{aligned}
& \Gamma=\epsilon \delta x\left(B_{H}, S_{L}\right)\left\{\left(B_{H}-S_{L}\right)-v\left(B_{H}\right)-v\left(S_{L}\right)\right\} \\
& +(1-\epsilon) \delta x\left(B_{H}, S_{H}\right)\left\{\left(B_{H}-S_{H}\right)-v\left(B_{H}\right)-v\left(S_{H}\right)\right. \\
& \left.-\frac{\epsilon}{1-\epsilon}\left(S_{H}-S_{L}-v\left(S_{L}\right)+v\left(S_{H}\right)\right)\right\} \\
& +\epsilon(1-\delta) x\left(B_{L}, S_{L}\right)\left\{\left(B_{L}-S_{L}\right)-v\left(B_{L}\right)-v\left(S_{L}\right)\right. \\
& -\frac{\delta}{1-\delta}\left(B_{H}-B_{L}-v\left(B_{H}\right)+v\left(B_{L}\right)\right\} \\
& +(1-\epsilon)(1-\delta) x\left(B_{L}, S_{H}\right)\left\{\left(B_{L}-S_{H}\right)-v\left(B_{L}\right)-v\left(S_{H}\right)\right. \\
& -\frac{\delta}{1-\delta}\left(B_{H}-B_{L}-v\left(B_{H}\right)+v\left(B_{L}\right)\right. \\
& \left.-\frac{\epsilon}{1-\epsilon}\left(S_{H}-S_{L}-v\left(S_{L}\right)+v\left(S_{H}\right)\right)\right\} \\
& +\delta v\left(B_{H}\right)+(1-\delta) v\left(B_{L}\right) \quad \text { (inside options for buyer }(\text { for } \mathrm{x}=0) \text { ) } \\
& \left.+\epsilon v\left(S_{L}\right)+(1-\epsilon) v\left(S_{H}\right) \quad \text { (inside options for buyer (for } \mathrm{x}=0\right) \text { ) } \\
& \text { - } \delta\left(v\left(B_{H}\right)-v\left(B_{L}\right)\right) \quad\left(- \text { Autarkic Rent of } B_{H}\left(\text { for } X\left(B_{L}\right)=0\right)\right) \\
& \text { - } \epsilon\left(v\left(S_{L}\right)-v\left(S_{H}\right)\right) \quad\left(- \text { Autarkic rent of } S_{L}\left(\text { for } X\left(S_{H}\right)=0\right)\right)
\end{aligned}
$$

A new feature, apart from non-trivial outside options, is the information rent induced by assigning property to the "bad" types.

The first assumption in the proposition ensures that $x\left(B_{H}, S_{H}\right)=1$ and $x\left(B_{L}, S_{L}\right)<$ 1. The derivation of the exact form of $x\left(B_{L}, S_{L}\right)$ is straightforward. It remains to be checked whether the individual-rationality constraints of the "good" types $B_{H}, S_{L}$ are fulfilled. Notice that

$$
\begin{aligned}
U\left(B_{H}\right) & =\left(B_{H}-B_{L}\right) X\left(B_{L}\right)+\left(1-X\left(B_{L}\right)\right)\left(v\left(B_{H}\right)-v\left(B_{L}\right)\right)+U\left(B_{L}\right) \geq v\left(B_{H}\right) \\
& \Leftrightarrow X\left(B_{L}\right)\left(\left(B_{H}-B_{L}\right)-\left(v\left(B_{H}\right)-v\left(B_{L}\right)\right) \geq 0\right. \\
& \Leftrightarrow\left(B_{H}-B_{L}\right) \geq v\left(B_{H}\right)-v\left(B_{L}\right)
\end{aligned}
$$

The condition for $S$ amounts to $\left(S_{H}-S_{L}\right) \geq v\left(S_{L}\right)-v\left(S_{H}\right)$.

\section{Proof of Proposition 4}

We show two examples in which both effects can be dominating. We fix one set of parameters such that for small $k=v\left(B_{L}\right)$ non-integration is optimal and for bigger $k$ buyer-integration is preferred. Set $B_{H}=11, S_{H}=7.8, B_{L}=4, S_{L}=0, \epsilon=0.5, \delta=$ $0.1, \alpha=1$. A tedious calculation shows that $\frac{\partial U}{\partial k} \mid k=0<0$ and $U(k=1)>U(k=0)$. Note that a bigger $\alpha$ strenghtens non-integration because it decreases $x\left(B_{L}, S_{L}\right)$ further. The reason for this is that a higher outside option of $B_{H}$ (for fixed $v\left(B_{L}\right)$ ) increases the information rent to be paid to $B_{H}$. 


\section{Proof of Proposition 5}

If $\alpha=v\left(B_{H}\right) / v\left(B_{L}\right)=v\left(S_{L}\right) / v\left(S_{H}\right)$ is suffiently increased, seller-integration becomes the preferred assignment of ownership.

We can fix a set of parameters to show that buyer-integration can be optimal. The parameters are:

$B_{H}=20, S_{H}=9, B_{L}=2, S_{L}=0, \epsilon=\frac{1}{5}, \delta=\frac{2}{3}, v\left(B_{L}\right)=v\left(S_{H}\right)=\frac{1}{100}, \alpha=1.01$. 


\section{References}

[1] d'Aspremont, Claude, Cremer, Jacques and Gerard-Varet, LouisAndre "Incentives and the Existence of Pareto-Optimal Revelation Mechanisms," Journal-of-Economic-Theory, August 1990, 51(2), pp. 257-82.

[2] Ausubel, Lawrence M. and Deneckere, Raymond J. "Efficient Sequential Bargaining," Review-of-Economic-Studies, April 1993, 60(2), pp. 435-61.

[3] Bester, Helmut and Strausz Roland "Contracting with Imperfect Commitment and the Revelation Principle: The Single Agent Case" Econometrica, July 2001, 69(4), pp.1077-1098.

[4] Che, Yeon-Koo and Hausch, Donald B. "Cooperative Investments and the Value of Contracting," American Economic Review, March 1999, 89(1), pp. 125-147.

[5] Coase, Ronald H. (1937) "The Nature of the Firm," Economica, 6(1), pp.173183

[6] Cramton, Peter and Gibbons, Robert and Klemperer, Paul "Dissolving a Partnership Efficiently," Econometrica, May 1987, 55(3), pp. 615-32.

[7] Cremer, Jacques and McLean, Richard P. "Optimal Selling Strategies under Uncertainty for a Discriminating Monopolist When Demands Are Interdependent," Econometrica, March 1985, 53(2), pp. 345-361.

[8] Cremer, Jacques and McLean, Richard P. "Full Extraction of the Surplus in Bayesian and Dominant Strategy Auctions," Econometrica, November 1988, 56(6), pp. 1247-1257.

[9] Dasgupta, Partha S., Hammond, Peter J. and Maskin, Eric S. "The Implementation of Social Choice Rules: Some General Results on Incentive Compatibility," Review-of-Economic-Studies, April 1979, 46(2), pp. 185-216.

[10] Edlin, Aaron S. and Hermalin, Benjamin E. "Contract Renegotiation in Agency Problems", mimeo.

[11] Fudenberg, Drew and Tirole, Jean "Moral Hazard and Renegotiation in Agency Contracts" Econometrica, November 1990, 58(6), pp. 1279-1319.

[12] Fudenberg, Drew and Tirole, Jean "Game Theory", Cambridge, Mass. and London: MIT Press, 1991, pages xxiii, 579.

[13] Gibbard Allan "Manipulation of Voting Schemes," Econometrica, July 1973, 41(4), pp. 587-601. 
[14] Green, Jerry and Laffont, Jean-Jacques "Characterization of Satisfactory Mechanisms for the Revelation of Preferences for Public Goods," Econometrica, July 1977, 45(2), pp. 427-38.

[15] Gresik, Thomas A.(1991a)"Ex Ante Efficient, Ex Post Individually Rational Trade," Journal-of-Economic-Theory, February 1991, 53(1), pp. 131-145.

[16] Gresik, Thomas A.(1991b) "Efficient Bilateral Trade with Statistically Dependent Beliefs," Journal of Economic Theory, February 1991, 53(1), pp 199-205.

[17] Grossman, Sanford J. and Hart, Oliver D. "The Costs and Benefits of Ownership: A Theory of Vertical and Lateral Integration," Journal of Political Economy, August 1986, 94(4), pp.691-719.

[18] Gul, Faruk "Unobservable Investment and the Hold-Up Problem," forthcoming Econometrica

[19] Hagedorn, Marcus "Approaching a Foundation of Incomplete Contracting: When do unforeseen contingencies matter?", mimeo.

[20] Harris, Milton and Raviv, Artur "Allocation Mechanisms and the Design of Auctions," Econometrica, November 1981, 49(6), pp. 1477-1499.

[21] Hart, Oliver and Moore, John "Incomplete Contracts and Renegotiation," Econometrica, July 1988, 56(4), pp. 755-785.

[22] Hart, Oliver and Moore, John "Property Rights and the Nature of the Firm," Journal-of-Political-Economy, December 1990, 98(6), pp. 1119-58.

[23] Hart, Oliver and Moore, John(1998) "Cooperative Vs. Outside Ownership", NBER Working Paper 6421.

[24] Hart, Oliver and Moore, John "Foundations of Incomplete Contracts," Review-of-Economic-Studies, December 1999, 66(1), pp. 115-38.

[25] Hart, Oliver "Firms, contracts, and financial structure," Clarendon Lectures in Economics, Oxford and New York: Oxford University Press, Clarendon Press, 1995, pages viii, 228.

[26] Holmström, Bengt and Myerson, Roger B." Efficient and Durable Decision Rules with Incomplete Information," Econometrica, November 1983, 51(6), pp. 1799-1819.

[27] Holmstrom, Bengt and Roberts, John "The Boundaries of the Firm Revisited," Journal-of-Economic-Perspectives, Fall 1998, 12(4), pp. 73-94. 
[28] Kennan, John and Wilson, Robert "Bargaining with Private Information," Journal-of-Economic-Literature, March 1993, 31(1), pp. 45-104.

[29] Krasa, Stefan (1999) "Unimprovable Allocations in Economies with Incomplete Information," Journal of Economic Theory, July 1999, 87(1), pp. 144168.

[30] Laffont, Jean-Jacques and Martimort, David "Collusion under Asymmetric Information," Econometrica, July 1997, 65(4), pp. 875-911.

[31] Laffont, Jean-Jacques and Martimort, David "Mechanism Design with Collusion and Correlation" Econometrica, March 2000, 68(2), pp. 309-342.

[32] Mailath, George J. and Postlewaite, Andrew "Asymmetric Information Bargaining Problems with Many Agents," Review-of-Economic-Studies, July 1990, 57(3), pp. 351-367.

[33] Maskin, Eric and Moore, John "Implementation and Renegotiation," Review-of-Economic-Studies, January 1999, 66(1), pp. 39-56

[34] Maskin, Eric and Tirole, Jean(1999b) "Two Remarks on the PropertyRights Literature," Review-of-Economic-Studies, January 1999, 66(1), pp. 139-149.

[35] Matouschek Niko(2002) "Increasing Lock-in to Facilitate Decision Making: Information and the Optimal Ownership Structure of Firms," mimeo.

[36] Matsuo, Toshihide "On Incentive Compatible, Individual Rational, and Ex Post Efficient Mechanisms for Bilateral Trading," Journal of Economic Theory, October 1989, 49(1), pp. 189-94.

[37] McAfee, R. Preston and Reny, Philip J. "Correlated Information and Mechanism Design," Econometrica, March 1992, 60(2), pp. 395-421.

[38] Muthoo Abhinay "Bargaining Theory with Apllications," Cambridge: Cambridge Univerity Press.

[39] Myerson, Roger B. "Incentive Compatibility and the Bargaining Problem," Econometrica, January 1979, 47(1), pp. 61-73.

[40] Myerson, Roger B. "Optimal Auction Design," Mathematics of Operations Research,1981, 6, pp. 58-73.

[41] Myerson, Roger B. "Optimal Coordination Mechanisms in Generalized Principal-Agent Problems," Journal-of-Mathematical-Economics, June 1982, 10(1), pp. 67-81. 
[42] Myerson, Roger B. and Satterthwaite, Mark A. "Efficient Mechanisms for Bilateral Trading," Journal-of-Economic-Theory, April 1983, 29(2), pp. 265-281.

[43] Neeman, Zvika "Property Rights and Efficiency of Voluntary Bargaining under Asymmetric Information," Review-of-Economic-Studies, July 1999, 66(3), pp. 679-691.

[44] Neeman, Zvika(2000) "The Relevance of Private Information in Mechanism Design," Working Paper, available at http://econ.bu.edu/neeman/ .

[45] Reiche, Sönje(2001) "Sequenttial Screening, Renegotiation and Incompleteness of Contracts, mimeo.

[46] Rob, Rafael "Pollution Claim Settlements under Private Information," Journal-of-Economic-Theory, April 1989, 47(2), pp. 307-333.

[47] Rogerson, William P. "Contractual Solutions to the Hold-Up Problem," Review-of-Economic-Studies, October 1992, 59(4), pp. 777-793.

[48] Rubinstein Ariel and Wolinsky Asher "Renegotiation-Proof Implementation and Time Preferences," American-Economic-Review, June 1992, 82(3), pp. 600-614.

[49] Schmitz Patrick W. (2002a) "Simple Contracts, Renegotiation Under Asymmetric Information, and the Hold-Up Problem," forthcoming European Economic Review.

[50] Schmitz Patrick W. (2002b) "On the Interplay of Hidden Action and Hidden Information in Simple Bilateral Trading Problems," Journal-of-EconomicTheory, April 2002, 103(2), pp. 444-460.

[51] Segal Ilya and Whinston Michael D. "The Mirrlees Approach to Mechanism Design with Renegotiation (with Applications to Hold-up and RiskSharing)," mimeo.

[52] Tirole, Jean "Procurement and Renegotiation," Journal of Political Economy, April 1986, 94(2), pp. 235-259.

[53] Williams, Steven R. "Efficient Performance in Two Agent Bargaining," Journal of Economic Theory, February 1987, 41(1), pp. 154-172.

[54] Williamson, Oliver E. "The Economic Insitutions of Capitalism," New York: Free Press. 


\section{IZA Discussion Papers}

\begin{tabular}{|c|c|c|c|c|}
\hline No. & Author(s) & Title & Area & Date \\
\hline 675 & $\begin{array}{l}\text { J. Konings } \\
\text { O. Kupets } \\
\text { H. Lehmann }\end{array}$ & $\begin{array}{l}\text { Gross Job Flows in Ukraine: Size, Ownership } \\
\text { and Trade Effects }\end{array}$ & 4 & $12 / 02$ \\
\hline 676 & A. Voicu & $\begin{array}{l}\text { Agriculture: Transition Buffer or Black Hole? A } \\
\text { Three-State Model of Employment Dynamics }\end{array}$ & 4 & $12 / 02$ \\
\hline 677 & $\begin{array}{l}\text { F. Galindo-Rueda } \\
\text { A. Vignoles }\end{array}$ & $\begin{array}{l}\text { Class Ridden or Meritocratic? An Economic } \\
\text { Analysis of Recent Changes in Britain }\end{array}$ & 2 & $12 / 02$ \\
\hline 678 & $\begin{array}{l}\text { M. Barbie } \\
\text { M. Hagedorn } \\
\text { A. Kaul }\end{array}$ & $\begin{array}{l}\text { Fostering Within-Family Human Capital } \\
\text { Investment: An Intragenerational Insurance } \\
\text { Perspective of Social Security }\end{array}$ & 3 & $12 / 02$ \\
\hline 679 & $\begin{array}{l}\text { A. Kölling } \\
\text { C. Schnabel } \\
\text { J. Wagner }\end{array}$ & $\begin{array}{l}\text { Establishment Age and Wages: Evidence from } \\
\text { German Linked Employer-Employee Data }\end{array}$ & 1 & $12 / 02$ \\
\hline 680 & $\begin{array}{l}\text { M. Hagedorn } \\
\text { A. Kaul }\end{array}$ & $\begin{array}{l}\text { Langzeitarbeitslosigkeit in Deutschland: Fakten, } \\
\text { Ursachen und Bekämpfung }\end{array}$ & 7 & $12 / 02$ \\
\hline 681 & $\begin{array}{l}\text { M. Hagedorn } \\
\text { A. Kaul } \\
\text { T. Mennel }\end{array}$ & $\begin{array}{l}\text { An Adverse Selection Model of Optimal } \\
\text { Unemployment Insurance }\end{array}$ & 7 & $12 / 02$ \\
\hline 682 & B. Cockx & $\begin{array}{l}\text { Vocational Training of Unemployed Workers in } \\
\text { Belgium }\end{array}$ & 2 & $01 / 03$ \\
\hline 683 & E. Strobl & $\begin{array}{l}\text { Is Education Used as a Signaling Device for } \\
\text { Productivity in Developing Countries? Evidence } \\
\text { from Ghana }\end{array}$ & 4 & $01 / 03$ \\
\hline 684 & P. A. Puhani & $\begin{array}{l}\text { The Rise and Fall of Swiss Unemployment: } \\
\text { Relative Demand Shocks, Wage Rigidities, and } \\
\text { Temporary Immigrants }\end{array}$ & 2 & $01 / 03$ \\
\hline 685 & $\begin{array}{l}\text { L. Borghans } \\
\text { B. ter Weel }\end{array}$ & $\begin{array}{l}\text { Do We Need Computer Skills to Use a } \\
\text { Computer? Evidence from Britain }\end{array}$ & 2 & $01 / 03$ \\
\hline 686 & $\begin{array}{l}\text { A. S. Kalwij } \\
\text { R. Alessie }\end{array}$ & $\begin{array}{l}\text { Permanent and Transitory Wage Inequality of } \\
\text { British Men, 1975-2001: Year, Age and Cohort } \\
\text { Effects }\end{array}$ & 2 & $01 / 03$ \\
\hline 687 & $\begin{array}{l}\text { I. Haouas } \\
\text { M. Yagoubi } \\
\text { A. Heshmati }\end{array}$ & $\begin{array}{l}\text { Labour-Use Efficiency in Tunisian Manufacturing } \\
\text { Industries }\end{array}$ & 4 & $01 / 03$ \\
\hline 688 & $\begin{array}{l}\text { I. Haouas } \\
\text { M. Yagoubi } \\
\text { A. Heshmati }\end{array}$ & $\begin{array}{l}\text { The Impacts of Trade Liberalization on } \\
\text { Employment and Wages in Tunisian Industries }\end{array}$ & 4 & $01 / 03$ \\
\hline 689 & $\begin{array}{l}\text { A. Heshmati } \\
\text { I. Haouas }\end{array}$ & $\begin{array}{l}\text { The Effects of Union Wage-Settings on Firms' } \\
\text { Production Factor Decisions }\end{array}$ & 5 & $01 / 03$ \\
\hline 690 & M. Hagedorn & Contracting with Private Information & 1 & $01 / 03$ \\
\hline
\end{tabular}

An updated list of IZA Discussion Papers is available on the center's homepage www.iza.org. 